\title{
New Phenalenone Derivatives: Synthesis and Evaluation of Their Singlet Oxygen Quantum Yield
}

\author{
Jérémy Godard, Frédérique Brégier, Philippe Arnoux, Bauyrzhan Myrzakhmetov, Yves Champavier, \\ Céline Frochot, and Vincent Sol*
}

Cite This: ACS Omega 2020, 5, 28264-28272

Read Online

\section{ACCESS | Lill Metrics \& More | 回 Article Recommendations ｜（） Supporting Information}

ABSTRACT: $1 H$-Phenalen-1-one is a very efficient and easy-to-synthesize photosensitizer. Many substitutions have been previously described, but most of them significantly reduce the singlet oxygen quantum yield. The chloromethyl derivative described elsewhere is a good starting point for the synthesis of many useful derivatives because of the methylene bridge that saves its unique photosensitizing properties. Eighteen new phenalenone derivatives have been synthesized, bearing amine, carboxylic acid, alcohol, azide, and other major functional groups in organic chemistry. These reactions were carried out in good-to-excellent yields, and most of these new compounds retained the singlet oxygen quantum yield of the parent molecule. These new derivatives are very promising precursors for a number of applications such as the development of photosensitive antimicrobial agents or materials.

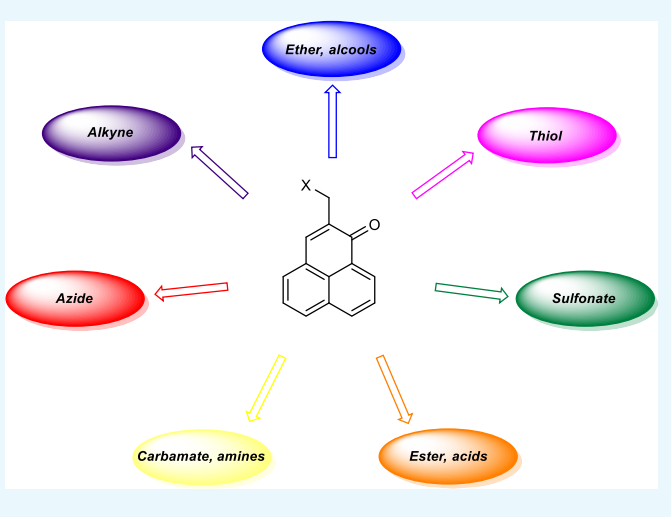

\section{INTRODUCTION}

1H-Phenalen-1-one, also known as perinaphthenone or simply phenalenone $(\mathrm{PN})$, is an oxygenated polycyclic aromatic hydrocarbon bearing a ketone moiety. This skeleton is found in several plant or fungal compounds, which are thought to play roles in the protection of organisms against external aggressions (e.g., phytoalexins). ${ }^{1}$ Some of these natural or natural-like phenalenones have demonstrated moderate-togood activities against fungi, ${ }^{2}$ as well as against human cancer cells, ${ }^{3}$ but PN is mostly recognized as a type-II photosensitizer that, upon irradiation with blue light, is able to produce singlet oxygen with a very high quantum yield. ${ }^{4}$ Several recent reports have described successful photodynamic treatments of fungi, ${ }^{5}$ bacteria, $^{6}$ or parasites ${ }^{7}$ based on the use of phenalenone derivatives. It appears that singlet oxygen production is highly influenced by substitutions on the PN skeleton. Addition of electron-withdrawing moieties ${ }^{5,8}$ or a methylene bridge ${ }^{9}$ does not seem to influence the singlet oxygen quantum yield, contrary to electron-donating moieties ${ }^{5,10}$ or conjugation elongation $^{1}$ that significantly decreases the photosensitizer capabilities. Based on the previous work of Späth et al., which only described the synthesis of ammonium derivatives, ${ }^{11}$ we present in this article the functionalization of phenalenone with some of the main organic functions along with an evaluation of the singlet oxygen quantum yields of the synthesized derivatives.

\section{RESULTS AND DISCUSSION}

Phenalenone Synthesis and Chloromethylation. PN (1) was synthesized by the method of Song et al. ${ }^{7}$ and improved with the use of microwave activation (Scheme 1), which allowed a drastic reduction in reaction time from $3 \mathrm{~h}$ to

Scheme 1. Phenalenone Synthesis<smiles>c1ccc2ccccc2c1</smiles><smiles>O=C(Cl)/C=C/c1ccccc1</smiles>

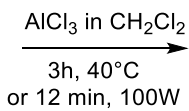<smiles>O=C1C=Cc2cccc3cccc1c23</smiles>

12 min. Multigram-scale reaction leads to a cost-effective production of $\mathrm{PN}$ with a very satisfactory purity (further purification is unnecessary).

Chloromethylation ${ }^{11}$ has been optimized by increasing the reaction time from 8 to $16 \mathrm{~h}$ (Scheme 2). This modification made it possible to obtain the chloromethyl derivative 2 $(\mathrm{PNCl})$ with a yield of $51 \%$, a noticeable increase compared with the $36 \%$ yield as reported in the original protocol. Replacing $\mathrm{HCl}$ with $\mathrm{HBr}$ allowed us to obtain the bromomethyl derivative $3(\mathrm{PNBr})$, although with a lower yield (37\%).

Received: August 28, 2020

Accepted: October 13, 2020

Published: October 23, 2020 
Scheme 2. Phenalenone Halomethylation

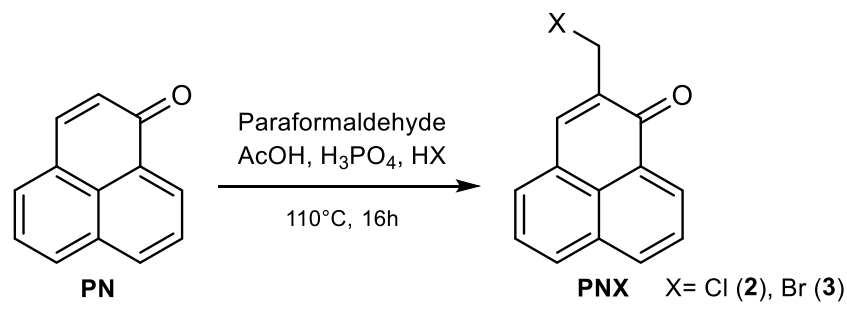

Functionalization of the PNXs. PNCl has been previously used in the synthesis of amine and ether derivatives of PN. ${ }^{7,11,12}$ The halogen moiety is prone to react at room temperature with a variety of anionic compounds (Scheme 3 ).

Scheme 3. Reactions of PNXs with Various Nucleophiles

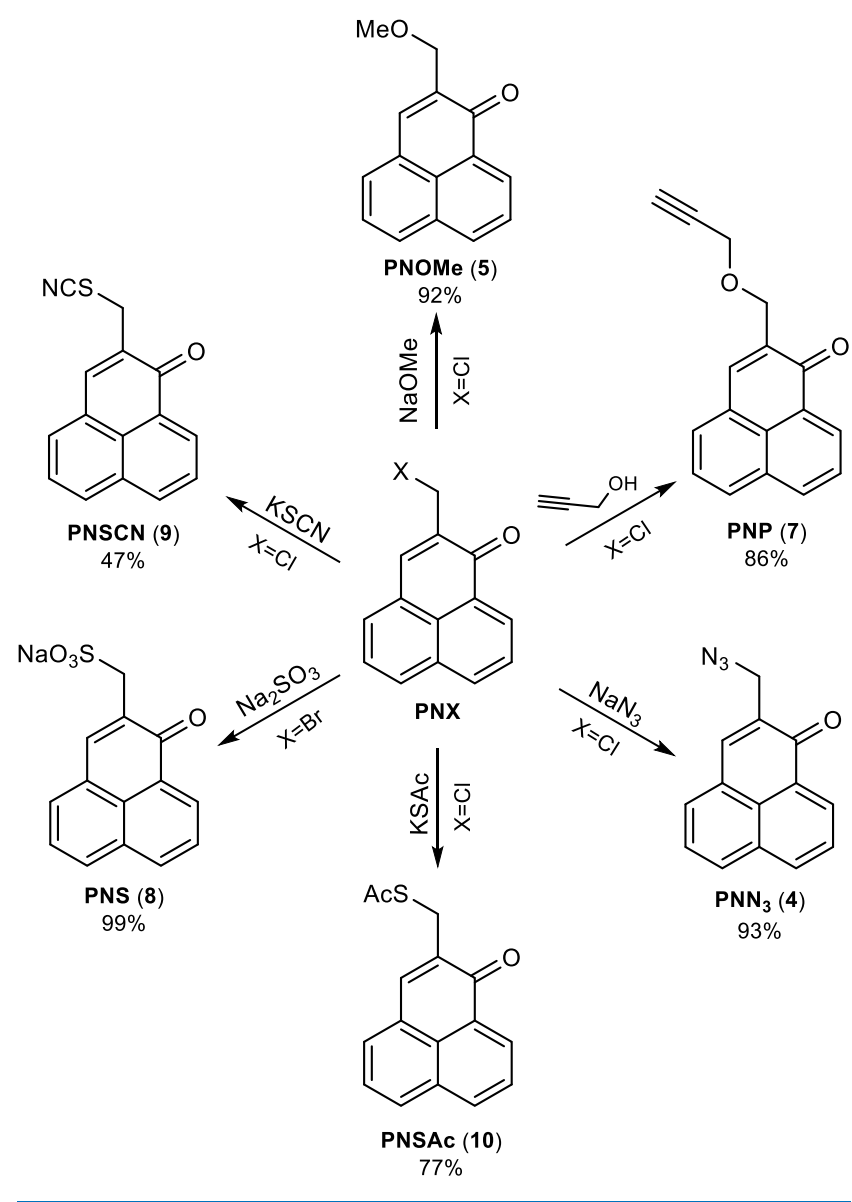

Reaction of $\mathrm{PNCl}$ with sodium methoxide in $\mathrm{MeOH} /$ $\mathrm{CH}_{2} \mathrm{Cl}_{2}$ mixture gave the methyl ether 5 (PNOMe) in $92 \%$ yield. Demethylation of PNOMe in the presence of $\mathrm{BBr}_{3}$ resulted in the formation of the corresponding alcohol 6 $(\mathrm{PNOH})$, also in excellent yield (88\%) (Scheme 4).

The propargylated phenalenone 7 (PNP) was obtained from $\mathrm{PNCl}$ by etherification in $86 \%$ yield under phase-transfer catalytic conditions using a quaternary ammonium salt as the catalyst and aqueous sodium hydroxide as the base. ${ }^{11}$

The sulfonate derivative 8 ( $\mathrm{PNS}$ ) was obtained by reaction of $\mathrm{Na}_{2} \mathrm{SO}_{3}$ with $\mathrm{PNBr}$ in a $\mathrm{CHCl}_{3} / \mathrm{MeOH} / \mathrm{H}_{2} \mathrm{O}$ mixture in the presence of a surfactant during $6 \mathrm{~h}$. The synthesis of a few sulfonated phenalenones has been already described, but, because of the experimental conditions (concentrated $\mathrm{H}_{2} \mathrm{SO}_{4}$
Scheme 4. Alcohol Derivative Synthesis<smiles>COCC1=Cc2cccc3c(OC)ccc(c23)C1=O</smiles><smiles>O=C1C(CO)=Cc2cccc3cccc1c23</smiles>

at $180{ }^{\circ} \mathrm{C}$ ), regioselectivity seemed to be difficult to control and substitution occurred in position 2 or $5 . .^{8,13}$ Even if, starting from $\mathrm{PN}$, the yield is lower (36\%) than those described in the literature $(47-55 \%)$, the present protocol ensures a rigorous regioselectivity under mild conditions.

The thiocyanate derivative 9 (PNSCN) was obtained by nucleophilic substitution of chlorine with KSCN in $47 \%$ yield.

The thioacetate derivative 10 (PNSAc) was synthesized by reaction of $\mathrm{PNCl}$ with potassium thioacetate during $4 \mathrm{~h}$ in $\mathrm{MeOH}$ under an inert atmosphere. After chromatographic separation, PNSAc was isolated in $77 \%$ yield. Thioacetate was converted to thiol by treatment of PNSAc with $\mathrm{K}_{2} \mathrm{CO}_{3}$ in $\mathrm{MeOH}$, under an inert atmosphere to avoid the formation of a disulfide bond; thiolated phenalenone 11 ( $\mathrm{PNSH}$ ) was obtained in $77 \%$ yield (Scheme 5).

\section{Scheme 5. Thiol Derivative Synthesis}<smiles>Nc1ccc2c3c(cccc13)C=C(CSC1CC1)C2=O</smiles>

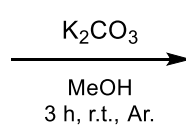<smiles></smiles>

The azide derivative $4\left(\mathrm{PNN}_{3}\right)$ was synthesized by the action of sodium azide in $\mathrm{MeOH} / \mathrm{H}_{2} \mathrm{O}$ with a yield of $93 \%$. This derivative was further modified through Huisgen-1,3dipolar cycloaddition with propargylated compounds such as methyl propiolate or N-BOC-propargylamine to yield the methylester 12 (PNCOOMe) and carbamate 15 (PNBOC) derivatives, respectively. Conducted at room temperature, these reactions proceeded very quickly and cleanly to afford the corresponding compounds in almost quantitative yields. Acid hydrolysis of PNCOOMe and PNBOC led, respectively, to the carboxylic acid 13 (PNCOOH-A) and the ammonium chloride $16\left(\mathrm{PNNH}_{2}-\mathrm{A}\right)$ derivatives without further purification. Another acid derivative (PNCOOH-B, 14) was directly synthesized from $\mathrm{PNN}_{3}$ and 10-undecynoic acid in aqueous media.

The simplest amine derivative $\mathbf{1 7}\left(\mathrm{PNNH}_{2}-\mathrm{B}\right)$ was obtained by the classical Staudinger reduction with triphenylphosphine as the reducing agent, a method much more effective than the Gabriel synthesis $^{14}$ (93\% yield instead of 46\%) (Scheme 6).

All these functions can be easily used for the synthesis of new phenalenone derivatives. For example, amino derivatives are easily transformed via the formation of peptide bonds. An adamantane derivative (PNAda, 18) was obtained by reaction of the corresponding acyl chloride with $\mathrm{PNNH}_{2}-\mathrm{A}$ (16). A 
Scheme 6. Synthesis of Amino- and Acid Derivatives

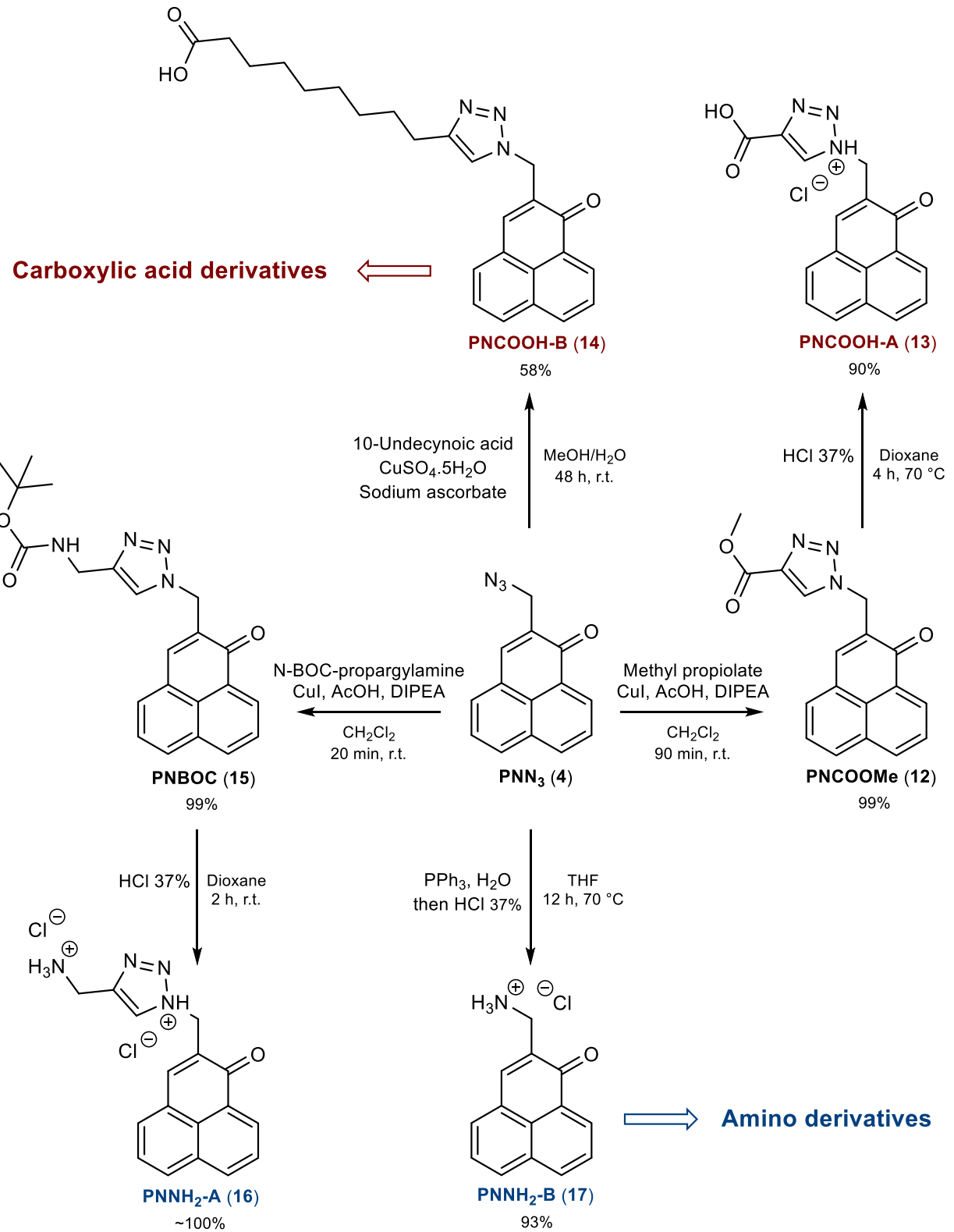

maleimide group was added after reaction between NHSactivated 6-maleimidohexanoic acid (MHA) with $\mathrm{PNNH}_{2}-\mathrm{B}$ (17) to obtain 19 (PNMal). The peptidic couplings were obtained in good yields regardless of the amino-PN used (Scheme 7).

In addition to adding amino or acid groups, the azide function can be used to attach other functions, for example, sugar moieties. A propargyl-glucose derivative has been attached to $\mathrm{PNN}_{3}(4)$ in good yield, and the resulting product 20 was then deprotected to obtain a new hydrosoluble neutral phenalenone $\mathbf{2 1}$ (Scheme 8).

The different phenalenone derivatives were characterized by NMR spectroscopy and high-resolution electro-spray mass spectrometry (see the Supporting Information).

Photophysical Properties. The photophysical data of all the compounds were obtained in $\mathrm{CHCl}_{3}$ (Table 1). Because of its insolubility in this solvent, PNS (8) was not tested.

The absorption spectra of the PN derivatives present two main absorption bands: the lower energetic band between 330 and $430 \mathrm{~nm}$ corresponding to a $\mathrm{n} \rightarrow \pi^{*}$ transition and the higher energetic band between 240 and $260 \mathrm{~nm}$ corresponding to a $\pi \rightarrow \pi^{*}$ transition. The $\mathrm{n} \rightarrow \pi^{*}$ transition exhibits a lower extinction coefficient than the $\pi \rightarrow \pi^{*}$ transition. The UVvisible spectrum of PNMal (19) displays an additional band probably because of the presence of the maleimide group (see the Supporting Information).

Singlet oxygen was measured by direct observation of singlet oxygen phosphorescence at $1270 \mathrm{~nm}$. The singlet oxygen quantum yields have been calculated in comparison with the free $\mathrm{PN}(\mathbf{1})$ in $\mathrm{CHCl}_{3}$ as reference (QY of 0.98$) .{ }^{4}$ Because of the presence of the methylene bridge, ${ }^{11,12}$ halogens, ethers, alcohols, amines, acids, and amide moieties do not impact the singlet oxygen quantum yield of the photosensitizers, that is close to unity. On the contrary, sulfur-based derivatives $\mathbf{9 , 1 0}$, and 11 exhibit significantly lower singlet oxygen quantum yields. To a certain extent, these results are not surprising, as sulfur groups are known to quench singlet oxygen either by physical or chemical process. ${ }^{15}$ The singlet oxygen lifetime 
Scheme 7. Examples of Peptidic Coupling

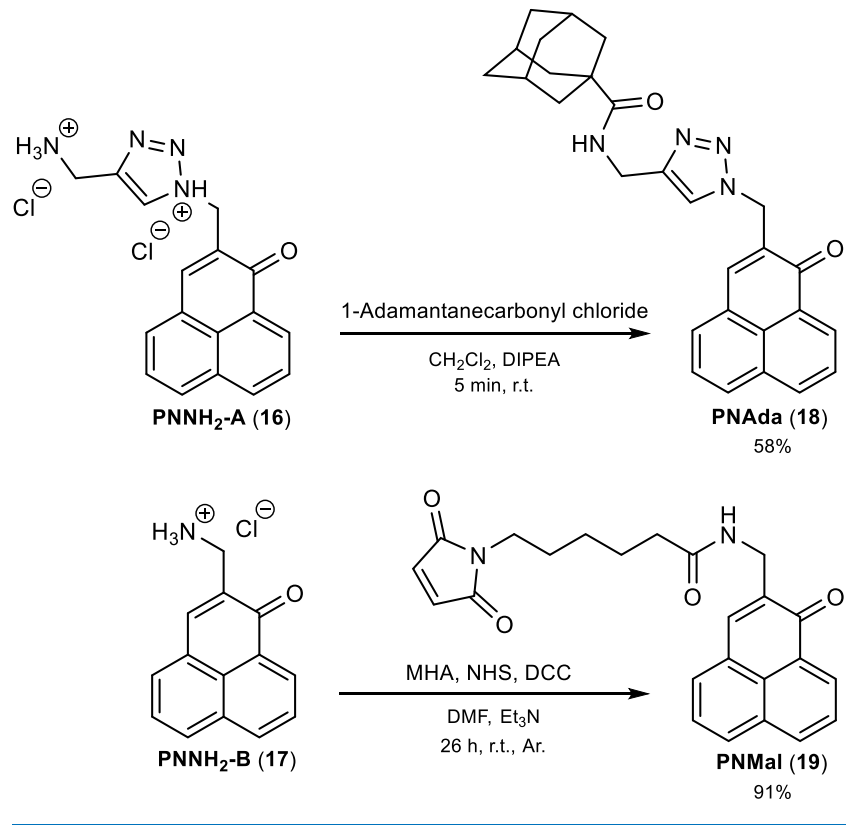

Scheme 8. Attachment of a Glucose Moiety

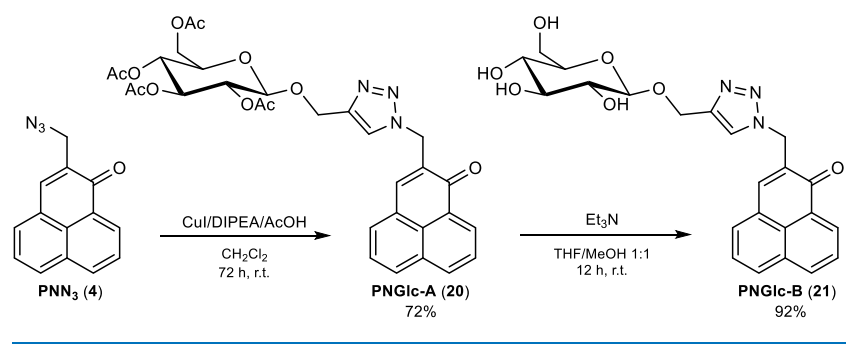

Table 1. Photophysical Data of the Different PN

\begin{tabular}{|c|c|c|c|c|}
\hline compounds & $\begin{array}{l}\text { fluorescence lifetime } \\
\text { (ns) }\end{array}$ & $\Phi f$ & $\begin{array}{c}{ }^{1} \mathrm{O}_{2} \text { lifetime } \\
(\mu \mathrm{s})\end{array}$ & $\Phi \Delta$ \\
\hline PN (1) & 5,7 & $<0.01$ & 199 & 0,98 \\
\hline $\mathrm{PNCl}(2)$ & 1,2 & $<0.01$ & 201 & 1,04 \\
\hline PNBr (3) & 5,7 & $<0.01$ & 174 & 0,71 \\
\hline $\mathrm{PNN}_{3}(4)$ & 1,2 & $<0.01$ & 203 & 0,81 \\
\hline PNOMe (5) & 6,2 & $<0.01$ & 205 & 0,79 \\
\hline PNOH (6) & 2,6 & $<0.01$ & 205 & 0,93 \\
\hline PNP (7) & 2,0 & $<0.01$ & 197 & 1,00 \\
\hline PNS (8) & ND & ND & ND & $\mathrm{ND}$ \\
\hline PNSCN (9) & 5,6 & $<0.01$ & 213 & 0,36 \\
\hline PNSAc (10) & 5,8 & $<0.01$ & 202 & 0,23 \\
\hline PNSH (11) & 5,6 & $<0.01$ & 204 & 0,13 \\
\hline PNCOOMe (12) & 5,9 & $<0.01$ & 189 & 1,14 \\
\hline $\begin{array}{l}\text { PNCOOH-A } \\
\text { (13) }\end{array}$ & 3,9 & $<0.01$ & 201 & 1,30 \\
\hline $\begin{array}{l}\text { PNCOOH-B } \\
\text { (14) }\end{array}$ & 4,7 & $<0.01$ & 201 & 1,11 \\
\hline PNBOC (15) & 2,6 & $<0.01$ & 203 & 1,07 \\
\hline $\mathrm{PNNH}_{2}-\mathrm{A}(16)$ & 0,6 & $<0.01$ & 198 & 1,11 \\
\hline $\mathrm{PNNH}_{2}-\mathrm{B}(17)$ & 3,7 & $<0.01$ & 189 & 1,07 \\
\hline PNAda (18) & 3,1 & $<0.01$ & 193 & 0,89 \\
\hline PNMal (19) & 4,8 & $<0.01$ & 206 & 1,00 \\
\hline PNGlc-A (20) & 5,6 & $<0.01$ & 197 & 1,15 \\
\hline PNGlc-B (21) & 3,0 & $<0.01$ & 178 & 1,15 \\
\hline
\end{tabular}

values in $\mathrm{CHCl}_{3}$ are homogeneous and grouped around the average value of $200 \mu \mathrm{s}$.
The relative fluorescence quantum yields of all the synthesized derivatives are very weak, less than $1 \%$ of that of quinine sulfate. As the first excited state of phenalenone proceeds from a $\mathrm{n} \rightarrow \pi^{*}$ transition, the fluorescence quantum yield is low because the de-excitation process is for the most part because of an intersystem crossing whose quantum yield is close to unity ${ }^{4}$ (see the Supporting Information).

In summary, this paper describes the synthesis and the characterization of 21 phenalenone derivatives, of which 18 are original; new reaction conditions or strategies used for some of them led us to improve the yield synthesis. Halogenomethylphenalenones are convenient precursors for a large range of phenalenone derivatives. The methylene bridge allows retaining the singlet oxygen quantum yield of the free $\mathrm{PN}$, but sulfur-based phenalenone derivatives have shown a lower production of singlet oxygen.

\section{EXPERIMENTAL SECTION}

General Information. All reagents and solvents were purchased from Alfa Aesar, TCI, Carlo Erba, Fisher Chemical, VWR, or Sigma Aldrich and were used as received.

Analytical thin-layer chromatography was performed on silica plates (Kieselgel 60 F254, thickness $0.2 \mathrm{~mm}$, Merck) and was revealed by direct observation and under a UV lamp at 345 $\mathrm{nm}$. Purifications by column chromatography were carried out using silica gel 60 (Merck, 0.015-0.040 mm).

NMR analyses were conducted on a Bruker DPX 500 NMR spectrometer, operating at $500 \mathrm{MHz}$ with tetramethylsilane as the reference. $\mathrm{s}=$ singlet, $\mathrm{d}=$ doublet, $\mathrm{dd}=$ double doublet, $\mathrm{t}=$ triplet, $\mathrm{q}=$ quartet, $\mathrm{q}^{5}=$ quintet.

High-resolution electrospray ionization mass spectra (HR ESI-MS) were performed at the ICOA/CBM (FR2708), Orléans university (France), with a Bruker Q-TOF maXis mass spectrometer coupled to an Ultimate 3000 RSLC chain (Dionex). Melting points were measured on a Kofler bench (Leica VMHB).

FT-IR analyses were realized on a FT-IR/NIR Frontier spectrometer (Perkin Elmer). st. = stretching, b. = bending, opb. = out of plane bending.

Absorption spectra were recorded on a UV-3600 UV-visible double-beam spectrophotometer (Shimadzu, Marne La Vallée, France). Fluorescence spectra were recorded on a Fluorolog FL3-222 spectrofluorometer (HORIBA Jobin Yvon, Longjumeau, France) equipped with a $450 \mathrm{~W}$ Xenon lamp, a thermostated cell compartment $\left(25^{\circ} \mathrm{C}\right)$, a UV-visible photomultiplier R928 (Hamamatsu, Japan), and an InGaAs infrared detector (DSS-16A020L Electro-Optical System Inc, Phoenixville, PA, USA). Excitation beam is diffracted by a double-ruled grating SPEX monochromator (1,200 grooves/ $\mathrm{mm}$ blazed at $330 \mathrm{~nm}$ ). Emission beam is diffracted by a double-ruled grating SPEX monochromator (1,200 grooves/ $\mathrm{mm}$ blazed at $500 \mathrm{~nm}$ ). Singlet oxygen emission was detected through a double-ruled grating SPEX monochromator (600 grooves/mm blazed at $1 \mu \mathrm{m})$ and a long-wave pass $(780 \mathrm{~nm})$. All spectra were obtained in four sides clear fluorometer quartz cuvettes. All the emission spectra (fluorescence and singlet oxygen luminescence) have been measured from solutions displaying the same absorbance at the excitation wavelength (less than 0.2).

Time-resolved experiments were performed using, for excitation, a pulsed laser diode emitting at $407 \mathrm{~nm}$ (LDH-PC-400M, fwhm $<70$ ps, $1 \mathrm{MHz}$ ) coupled with a PDL 800-D driver (both from PicoQuant $\mathrm{GmbH}$, Berlin, Germany) and, 
for detection, a SPCM-AQR-15 avalanche photodiode (EG \& G, Vaudreuil, Canada) coupled with a $550 \mathrm{~nm}$ long-wave pass filter as detection system. Acquisition was performed with a PicoHarp 300 module with a PHR-800 4 channel router (both from PicoQuant $\mathrm{GmbH}$, BERLIN, Germany). Fluorescence decays were recorded using the single photon counting method. Data were collected up to 1,000 counts accumulated in the maximum channel and analyzed using Time Correlated Single Photon Counting (TCSPC) software Fluofit (PicoQuant $\mathrm{GmbH}$, Berlin, Germany) based on iterative reconvolution using a Levensberg-Marquandt algorithm, enabling the obtention of multiexponential profiles (mainly one or two exponentials in our case).

Synthesis of the PN Derivatives. 1H-Phenalen-1-one 1 $(P N)$. PN was synthesized by applying the protocol described elsewhere ${ }^{7}$ without purification of the black tar to reach a yield of $58 \%$. This protocol has been improved with the use of microwave irradiation. Briefly, $960 \mathrm{mg}(7.5 \mathrm{mmol})$ of naphthalene and $1.25 \mathrm{~g}$ of cinnamoyl chloride were dissolved in $7.5 \mathrm{~mL}$ of $\mathrm{CH}_{2} \mathrm{Cl}_{2}$ and placed in an ice bath for $10 \mathrm{~min}$. $\mathrm{AlCl}_{3}(3 \mathrm{~g})$ was slowly added, and the mixture was stirred 10 min at $4{ }^{\circ} \mathrm{C}$. The reaction medium was then irradiated for 12 min at $100 \mathrm{~W}$ and then poured into $100 \mathrm{~mL}$ of $37 \% \mathrm{HCl}$ and filtered, and the filtrate was diluted in water before extraction with $\mathrm{CH}_{2} \mathrm{Cl}_{2}$ to obtain $780 \mathrm{mg}(4.3 \mathrm{mmol}, 57 \%)$ of a matt yellow powder. ${ }^{1} \mathrm{H}-\mathrm{NMR}\left(500 \mathrm{MHz}, \mathrm{CDCl}_{3}\right): \delta(\mathrm{ppm}) 8.64$ (dd, $J=1.1,7.4 \mathrm{~Hz}, 1 \mathrm{H}), 8.21(\mathrm{dd}, J=0.9,8.0 \mathrm{~Hz}, 1 \mathrm{H}), 8.03$ $(\mathrm{d}, J=8.5 \mathrm{~Hz}, 1 \mathrm{H}), 7.80(\mathrm{~d}, J=7.6 \mathrm{~Hz}, 1 \mathrm{H}), 7.76(\mathrm{~d}, J=9.8$ $\mathrm{Hz}, 1 \mathrm{H}), 7.76(\mathrm{~d}, J=9.6 \mathrm{~Hz}, 1 \mathrm{H}), 7.61(\mathrm{dd}, J=7.1,8.2 \mathrm{~Hz}$, $1 \mathrm{H}), 6.74(\mathrm{~d}, J=9.8 \mathrm{~Hz}, 1 \mathrm{H}) .{ }^{13} \mathrm{C}-\mathrm{NMR}(125 \mathrm{MHz}, \mathrm{CDCl} 3)$ : $\delta(\mathrm{ppm}) 185.67,141.76,134.89,132.20,131.92,131.34$, 130.38, 129.52, 129.28, 127.89, 127.59, 127.14, 126.64. FT-IR: $\nu\left(\mathrm{cm}^{-1}\right): 3039$ (Aromatic CH st.), 1635, 1622, 1571, 1505 ( $\mathrm{C}=\mathrm{O}$ st., $\mathrm{C}=\mathrm{C}$ st., CCC b.), 1392, 1356, 1284, 1236, 1183, 1121 (C=C st., CH b., CCC b.), 957, 828, 773, 732, 702, 614 (Aromatic-CH opb.). MS: HRMS $\left(\mathrm{ESI}^{+}\right.$), calcd for $\mathrm{C}_{13} \mathrm{H}_{9} \mathrm{O}$ $[\mathrm{M}+\mathrm{H}]^{+}$: 181.064791; found, 181.065003. MW: $180.21 \mathrm{~g} /$ mol. mp $153{ }^{\circ} \mathrm{C}$.

2-(Chloromethyl)-1H-phenalen-1-one 2 (PNCI). The procedure described elsewhere ${ }^{11}$ was improved by increasing the reaction time. Briefly, $9.72 \mathrm{~g}$ (54 mmol) of $\mathrm{PN}, 29.7 \mathrm{~g}$ of paraformaldehyde, $216 \mathrm{~mL}$ of glacial acetic acid, and $135 \mathrm{~mL}$ of $85 \%$ phosphoric acid were mixed and warmed at $110{ }^{\circ} \mathrm{C}$ until solubilization of the solids. Hydrochloric acid $(144 \mathrm{~mL}$, $37 \%$ ) was added, and the reaction was kept at $110^{\circ} \mathrm{C}$ for $16 \mathrm{~h}$. After cooling to room temperature, the solution was poured into $500 \mathrm{~mL}$ of ice and water and $\mathrm{pH}$ was increased with $5 \mathrm{M}$ $\mathrm{NaOH}$. The supernatant dark solid was filtered and washed with $1 \mathrm{M} \mathrm{NaHCO}$, and the product was extracted with $\mathrm{CH}_{2} \mathrm{Cl}_{2}$ and purified by column chromatography $\left(\mathrm{CH}_{2} \mathrm{Cl}_{2} / \mathrm{PE}\right.$ $1: 1)$ to yield $6.30 \mathrm{~g}(27.5 \mathrm{mmol}, 51 \%)$ of a bright yellow powder (litt. 36\%). ${ }^{1} \mathrm{H}-\mathrm{NMR}\left(500 \mathrm{MHz}, \mathrm{CDCl}_{3}\right): \delta(\mathrm{ppm})$ $8.68(\mathrm{dd}, J=1.1,7.4 \mathrm{~Hz}, 1 \mathrm{H}), 8.22(\mathrm{dd}, J=0.9,8.0 \mathrm{~Hz}, 1 \mathrm{H})$, $8.05(\mathrm{~d}, J=7.9 \mathrm{~Hz}, 1 \mathrm{H}), 7.94(\mathrm{~s}, 1 \mathrm{H}), 7.81(\mathrm{~m}, 2 \mathrm{H}), 7.62(\mathrm{dd}$, $J=7.1,8.2 \mathrm{~Hz}, 1 \mathrm{H}), 4.68(\mathrm{~d}, J=0.9 \mathrm{~Hz}, 2 \mathrm{H}) .{ }^{13} \mathrm{C}-\mathrm{NMR}(125$ $\left.\mathrm{MHz}, \mathrm{CDCl}_{3}\right): \delta(\mathrm{ppm}) 183.49,140.29,135.66,135.17$, 132.20, 132.06, 132.00, 130.92, 129.02, 127.31, 127.29, 127.21, 126.81, 41.39. FT-IR: $\nu\left(\mathrm{cm}^{-1}\right): 2968,2924$ (Aromatic CH st.), $1637,1623,1595,1578,1569,1507$ ( $C=\mathrm{O}$ st., $\mathrm{C}=\mathrm{C}$ st., CCC b.), 1424, 1403, 1394, 1361, 1270, 1253, 1227, 1191, 1124; 1027 (C=C st., CH b., CCC b.), 949, 937, 847, 790, 769, 670 (Aromatic-CH opb.). MS: HRMS (ESI ${ }^{+}$), calcd for
$\mathrm{C}_{14} \mathrm{H}_{10} \mathrm{ClO}[\mathrm{M}+\mathrm{H}]^{+}:$229.041469; found, 229.041619. MW: $228.7 \mathrm{~g} / \mathrm{mol} . \mathrm{mp} 143{ }^{\circ} \mathrm{C}$.

2-(Bromomethyl)-1H-phenalen-1-one 3 (PNBr). PN (9.02 g, $50 \mathrm{mmol}$ ), $27.5 \mathrm{~g}$ of paraformaldehyde, $200 \mathrm{~mL}$ of glacial acetic acid, and $125 \mathrm{~mL}$ of $85 \%$ phosphoric acid were mixed and warmed at $110{ }^{\circ} \mathrm{C}$ until solubilization of the solids. Hydrobromic acid (236 mL, 48\%) was added, and the reaction was kept at $110{ }^{\circ} \mathrm{C}$ for $16 \mathrm{~h}$. After cooling to room temperature, the solution was poured into $500 \mathrm{~mL}$ of ice and water and neutralized with $0.5 \mathrm{M} \mathrm{NaOH}$ and then with solid $\mathrm{K}_{2} \mathrm{CO}_{3}$. The supernatant dark solid was filtered and washed with $1 \mathrm{M} \mathrm{NaHCO}$, and the product was extracted with $\mathrm{CH}_{2} \mathrm{Cl}_{2}$ and purified by column chromatography $\left(\mathrm{CH}_{2} \mathrm{Cl}_{2} / \mathrm{PE}\right.$ $1: 1)$ to yield $5.05 \mathrm{~g}(18.5 \mathrm{mmol}, 37 \%)$ of a bright yellow powder. ${ }^{1} \mathrm{H}-\mathrm{NMR}\left(500 \mathrm{MHz}, \mathrm{CDCl}_{3}\right): \delta(\mathrm{ppm}) 8.69$ (dd, $J=$ $0.8,7.5 \mathrm{~Hz}, 1 \mathrm{H}), 8.22(\mathrm{~d}, J=8.1 \mathrm{~Hz}, 1 \mathrm{H}), 8.05(\mathrm{~d}, J=8.3 \mathrm{~Hz}$, $1 \mathrm{H}), 7.92(\mathrm{~s}, 1 \mathrm{H}), 7.81(\mathrm{~m}, 2 \mathrm{H}), 7.62(\mathrm{dd}, J=7.4,8.0 \mathrm{~Hz}$, $1 \mathrm{H}), 4.56(\mathrm{~s}, 2 \mathrm{H}) .{ }^{13} \mathrm{C}-\mathrm{NMR}\left(125 \mathrm{MHz}, \mathrm{CDCl}_{3}\right): \delta(\mathrm{ppm})$ 183.32 , 141.36, 136.36, 135.34, 132.52, 132.27, 132.20, 131.28, $129.25,127.61,127.56,127.45,127.01,28.34$. FT-IR: $\nu$ $\left(\mathrm{cm}^{-1}\right)$ : 3038, 2977 (Aromatic CH st.), 1635, 1621, 1595, 1568, 1507 ( $\mathrm{C}=\mathrm{O}$ st., $\mathrm{C}=\mathrm{C}$ st., CCC b.), 1417, 1404, 1391, $1358,1268,1257,1227,1205,1189,1111,1074,1043,1026$ (C=C st., CH b., CCC b.), 973, 943, 930, 887, 845, 787, 768, 748, 691, 630, 615 (Aromatic-CH opb.). MS: HRMS (ESI ${ }^{+}$), calcd for $\mathrm{C}_{14} \mathrm{H}_{10} \mathrm{BrO}[\mathrm{M}+\mathrm{H}]^{+}$: 272.990953; found, 272.990960. MW: $273.13 \mathrm{~g} / \mathrm{mol}$. mp $174{ }^{\circ} \mathrm{C}$.

2-(Azidomethyl)-1H-phenalen-1-one 4 (PNN $\left.N_{3}\right) . \quad \mathrm{PNCl}$ (3.42 g, $15 \mathrm{mmol})$ and $19.5 \mathrm{~g}(300 \mathrm{mmol})$ of $\mathrm{NaN}_{3}$ were dissolved in $1.08 \mathrm{~L}$ of $\mathrm{MeOH}$ and $120 \mathrm{~mL}$ of water. The solution was left under stirring for $24 \mathrm{~h}$ at room temperature. $\mathrm{MeOH}$ was evaporated, and the aqueous suspension was extracted with $\mathrm{CH}_{2} \mathrm{Cl}_{2}$. The organic phase was dried with brine and then over $\mathrm{MgSO}_{4}$ and evaporated. The crude was purified by column chromatography $\left(\mathrm{CH}_{2} \mathrm{Cl}_{2} / \mathrm{EP} 1: 1\right)$ to yield $3.28 \mathrm{~g}$ (14 mmol, 93\%) of a bright yellow powder. ${ }^{1} \mathrm{H}-\mathrm{NMR}(500$ $\left.\mathrm{MHz}, \mathrm{CDCl}_{3}\right): \delta(\mathrm{ppm}) 8.68(\mathrm{dd}, J=0.9,7.4 \mathrm{~Hz}, 1 \mathrm{H}), 8.24$ $(\mathrm{d}, J=8.0 \mathrm{~Hz}, 1 \mathrm{H}), 8.06(\mathrm{~d}, J=8.2 \mathrm{~Hz}, 1 \mathrm{H}), 7.82(\mathrm{~m}, 3 \mathrm{H})$, $7.63(\mathrm{dd}, J=7.2,8.1 \mathrm{~Hz}, 1 \mathrm{H}), 4.46(\mathrm{~s}, 2 \mathrm{H}) .{ }^{13} \mathrm{C}-\mathrm{NMR}(125$ $\left.\mathrm{MHz}, \mathrm{CDCl}_{3}\right): \delta(\mathrm{ppm}) 184.21,139.21,135.22,134.30$, $132.09,132.08,131.90,130.82,129.00,127.28,127.26,127.18$, 126.83, 50.05. FT-IR: $\nu\left(\mathrm{cm}^{-1}\right): 3049,2927$ (Aromatic CH st.), $2109\left(\mathrm{~N}_{3}\right.$ st. $), 1628,1570,1508$ ( $\mathrm{C}=\mathrm{O}$ st., $\mathrm{C}=\mathrm{C}$ st., CCC b.), 1388, 1247, 1176, 1025 (C=C st., CH b., CCC b.), 908, 838, 769, 700, 661 (Aromatic -CH opb.). MS: HRMS $\left(\mathrm{ESI}^{+}\right)$, calcd for $\mathrm{C}_{14} \mathrm{H}_{10} \mathrm{~N}_{3} \mathrm{O}\left[\mathrm{M}+\mathrm{H}^{+}\right.$: 236.081838; found, 236.081868. MW: $235.25 \mathrm{~g} / \mathrm{mol} . \mathrm{mp} 96{ }^{\circ} \mathrm{C}$.

2-(Methoxymethyl)-1H-phenalen-1-one 5 (PNOMe). $\mathrm{PNCl}$ $(1.82 \mathrm{~g}, 8 \mathrm{mmol})$ was dissolved in $80 \mathrm{~mL}$ of $\mathrm{MeOH}$ and $40 \mathrm{~mL}$ of $\mathrm{CH}_{2} \mathrm{Cl}_{2}$, and $8 \mathrm{~mL}(20 \mathrm{mmol})$ of $5 \mathrm{M}$ sodium methoxide in $\mathrm{MeOH}$ was slowly added. The solution was stirred for $1 \mathrm{~h}$ at room temperature, and the base was neutralized with concentrated $\mathrm{HCl}$, filtered, and evaporated. The crude was purified by column chromatography (eluent: $\mathrm{CHCl}_{3} / \mathrm{MeOH}$ 99:1) to yield $1.64 \mathrm{~g}(7.2 \mathrm{mmol}, 92 \%)$ of a bright yellow powder. ${ }^{1} \mathrm{H}-\mathrm{NMR}\left(500 \mathrm{MHz}, \mathrm{CDCl}_{3}\right): \delta(\mathrm{ppm}) 8.64(\mathrm{dd}, J=$ $0.8,7.4 \mathrm{~Hz}, 1 \mathrm{H}), 8.20(\mathrm{~d}, J=8.0 \mathrm{~Hz}, 1 \mathrm{H}), 8.00(\mathrm{~d}, J=8.3 \mathrm{~Hz}$, $1 \mathrm{H}), 7.82(\mathrm{~s}, 1 \mathrm{H}), 7.77(\mathrm{t}, J=7.6 \mathrm{~Hz}, 1 \mathrm{H}), 7.77(\mathrm{~d}, J=7.0 \mathrm{~Hz}$, $1 \mathrm{H}), 7.59$ (dd, $J=7.3,8.0 \mathrm{~Hz}, 1 \mathrm{H}), 4.55(\mathrm{~d}, J=1.2 \mathrm{~Hz}, 2 \mathrm{H})$, 3.56 (s, 3H). ${ }^{13} \mathrm{C}-\mathrm{NMR}\left(125 \mathrm{MHz}, \mathrm{CDCl}_{3}\right): \delta$ (ppm) 184.44, 137.30, 136.72, 134.91, 132.03, 131.39, 131.33 130.39, 129.21, 127.72, 127.07, 127.01, 126.79, 69.37, 59.02. FT-IR: $\nu\left(\mathrm{cm}^{-1}\right)$ : 2974, 2935, 2830 (Aromatic CH st.), 1630, 1571, 1507 (C=O 
st., $C=C$ st., CCC b.), 1447, 1396, 1247, 1191, 1109, 1021 ( $\mathrm{C}=\mathrm{C}$ st., $\mathrm{CH}$ b., CCC b.), 918, 839, 772, 672 (Aromatic $-\mathrm{CH}$ opb.). MS: HRMS (ESI $\left.{ }^{+}\right)$, calcd for $\mathrm{C}_{15} \mathrm{H}_{13} \mathrm{O}_{2}[\mathrm{M}+$ $\mathrm{H}]^{+}$: 225.091006; found, 225.091224. MW: $224.26 \mathrm{~g} / \mathrm{mol}$. mp $86{ }^{\circ} \mathrm{C}$.

2-(Hydroxymethyl)-1H-phenalen-1-one 6 (PNOH). PNOMe (1.64 g, $7.2 \mathrm{mmol})$ was dissolved in $35 \mathrm{~mL}$ of $\mathrm{CH}_{2} \mathrm{Cl}_{2}$, and $10 \mathrm{~mL}(10 \mathrm{mmol})$ of $1 \mathrm{M} \mathrm{BBr}_{3}$ in $\mathrm{CH}_{2} \mathrm{Cl}_{2}$ was slowly added. The orange solution was stirred for $90 \mathrm{~min}$ at room temperature. Thirty-five milliliters of $1 \mathrm{M} \mathrm{HCl}$ in water was added, and the resulting yellow organic phase was collected, washed with water and brine, dried over $\mathrm{MgSO}_{4}$, and evaporated. The crude was purified by column chromatography (eluent: $\mathrm{CHCl}_{3} / \mathrm{MeOH}$ 98:2 then 96.5:3.5) to yield $1.33 \mathrm{~g}(6.33 \mathrm{mmol}, 88 \%)$ of a bright yellow powder. ${ }^{1} \mathrm{H}-\mathrm{NMR}\left(500 \mathrm{MHz}, \mathrm{CDCl}_{3}\right): \delta(\mathrm{ppm}) 8.63(\mathrm{~d}, J=7.3 \mathrm{~Hz}$, $1 \mathrm{H}), 8.21(\mathrm{~d}, J=8.0 \mathrm{~Hz}, 1 \mathrm{H}), 8.01(\mathrm{~d}, J=8.3 \mathrm{~Hz}, 1 \mathrm{H}), 7.79(\mathrm{t}$, $J=7.7 \mathrm{~Hz}, 1 \mathrm{H}), 7.77(\mathrm{~d}, J=7.6 \mathrm{~Hz}, 1 \mathrm{H}), 7.73(\mathrm{~s}, 1 \mathrm{H}), 7.60(\mathrm{t}$, $J=7.6 \mathrm{~Hz}, 1 \mathrm{H}), 4.72(\mathrm{~s}, 2 \mathrm{H}), 3.03(\mathrm{~s}, 1 \mathrm{H}) .{ }^{13} \mathrm{C}-\mathrm{NMR}(125$ $\left.\mathrm{MHz}, \mathrm{CDCl}_{3}\right): \delta(\mathrm{ppm}) 185.88,138.31,137.97,135.26$, $132.01,131.79,131.77,130.59,129.13,127.44,127.15,127.08$, 126.83, 62.29. FT-IR: $\nu\left(\mathrm{cm}^{-1}\right): 3438(\mathrm{OH}), 2919,2890,2851$ (Aromatic CH st.), 1635, 1611, 1564, 1509 (C=O st., C =C st., CCC b.), 1450, 1398, 1361, 1263, 1242, 1179, 1125, 1073, 1002, 990 (C=C st., CH b., CCC b.), 892, 844, 778, 764, 724, 691, 666 (Aromatic-CH opb.). MS: HRMS (ESI ${ }^{+}$), calcd for $\mathrm{C}_{14} \mathrm{H}_{11} \mathrm{O}_{2}[\mathrm{M}+\mathrm{H}]^{+}:$211.075356; found, 211.074947. MW: $210.23 \mathrm{~g} / \mathrm{mol} . \mathrm{mp} 127^{\circ} \mathrm{C}$.

2-((Prop-2-yn-1-yloxy)methyl)-1H-phenalen-1-one 7 (PNP). $\mathrm{PNCl}(5 \mathrm{~g}, 21.8 \mathrm{mmol}), 5 \mathrm{~mL}(87.2 \mathrm{mmol})$ of propargyl alcohol, $220 \mathrm{~mL}$ of $\mathrm{CH}_{2} \mathrm{Cl}_{2}, 1.1 \mathrm{~g}(2.97 \mathrm{mmol})$ of tetrabutylammonium iodide, and $220 \mathrm{~mL}$ of $5 \mathrm{M}$ aq. $\mathrm{NaOH}$ were vigorously stirred for $24 \mathrm{~h}$ at room temperature. After completion of the reaction, $250 \mathrm{~mL}$ of $\mathrm{CH}_{2} \mathrm{Cl}_{2}$ was added, and the organic phase was washed with water and then with brine, dried over $\mathrm{MgSO}_{4}$, and evaporated. The crude was purified by column chromatography (eluent: $\mathrm{CH}_{2} \mathrm{Cl}_{2}$ ) to yield $4.63 \mathrm{~g}$ (18.6 mmol, 86\%) of a bright yellow powder. ${ }^{1} \mathrm{H}-\mathrm{NMR}(500$ $\left.\mathrm{MHz}, \mathrm{CDCl}_{3}\right): \delta(\mathrm{ppm}) 8.65(\mathrm{dd}, J=1.0,7.3 \mathrm{~Hz}, 1 \mathrm{H}), 8.21$ $(\mathrm{dd}, J=0.5,7.9 \mathrm{~Hz}, 1 \mathrm{H}), 8.01(\mathrm{~d}, J=8.2 \mathrm{~Hz}, 1 \mathrm{H}), 7.86(\mathrm{~s}$, $1 \mathrm{H}), 7.79$ (s, $1 \mathrm{H}), 7.78(\mathrm{t}, J=7.5 \mathrm{~Hz}, 1 \mathrm{H}), 7.60(\mathrm{dd}, J=7.2$, $8.1 \mathrm{~Hz}, 1 \mathrm{H}), 4.70(\mathrm{~d}, J=1.3 \mathrm{~Hz}, 2 \mathrm{H}), 4.36(\mathrm{~d}, J=2.4 \mathrm{~Hz}, 2 \mathrm{H})$, $2.50(\mathrm{t}, J=2.3 \mathrm{~Hz}, 1 \mathrm{H}) .{ }^{13} \mathrm{C}-\mathrm{NMR}\left(125 \mathrm{MHz}, \mathrm{CDCl}_{3}\right): \delta$ (ppm) 184.3, 137.83, 136.14, 134.96, 132.04, 131.53, 131.49, $130.46,129.18,127.62,127.11,127.07,126.80,79.62,74.82$, 66.79, 58.42. FT-IR: $\nu\left(\mathrm{cm}^{-1}\right): 3261$ (CH acetylenic st.), 2921, 2880, 2858 (Aromatic CH st.), 2111 (CC acetylenic st.), 1638, 1616, 1599, 1580, 1568 ( $\mathrm{C}=\mathrm{O}$ st., $\mathrm{C}=\mathrm{C}$ st., $\mathrm{CCC}$ b.), 1459, $1412,1395,1366,1347,1263,1241,1183,1158,1125,1100$, 1020 (C=C st., CH b., CCC b.), 924, 916, 843, 775, 762, 704, 651 (Aromatic $-\mathrm{CH}$ opb.). MS: HRMS $\left(\mathrm{ESI}^{+}\right)$, calcd for $\mathrm{C}_{17} \mathrm{H}_{13} \mathrm{O}_{2}[\mathrm{M}+\mathrm{H}]^{+}$: 249.091006; found, 249.091015. MW: $248.28 \mathrm{~g} / \mathrm{mol} . \mathrm{mp} 130{ }^{\circ} \mathrm{C}$.

Sodium (1-oxo-1H-Phenalen-2-yl)methanesulfonate 8 (PNS). PNBr (273 mg, $1 \mathrm{mmol}), 504 \mathrm{mg}$ (4 mmol) of sodium sulfite, and $369 \mathrm{mg}(1 \mathrm{mmol})$ of tetrabutylammonium iodide were dissolved in a $\mathrm{CHCl}_{3} / \mathrm{MeOH} / \mathrm{H}_{2} \mathrm{O}(8: 1: 1)$ mixture and vigorously stirred at room temperature for $6 \mathrm{~h}$. The solvents were then evaporated, and the crude was adsorbed onto Florisil and purified by column chromatography (eluent: $\mathrm{CHCl}_{3} / \mathrm{MeOH}$ 7:3 to $\mathrm{CHCl}_{3} / \mathrm{MeOH} / \mathrm{H}_{2} \mathrm{O}$ 6:4:1) to yield $295 \mathrm{mg}$ (0.99 mmol, 99\%) of a matt yellow powder. ${ }^{1} \mathrm{H}-\mathrm{NMR}$ $\left(500 \mathrm{MHz}, \mathrm{CD}_{3} \mathrm{OD}\right): \delta(\mathrm{ppm}) 8.64(\mathrm{dd}, J=0.9,7.3 \mathrm{~Hz}, 1 \mathrm{H})$, $8.36(\mathrm{~d}, J=7.6 \mathrm{~Hz}, 1 \mathrm{H}), 8.16(\mathrm{~d}, J=8.0 \mathrm{~Hz}, 1 \mathrm{H}), 8.15(\mathrm{~s}$, $1 \mathrm{H}), 7.94(\mathrm{~d}, J=7.0 \mathrm{~Hz}, 1 \mathrm{H}), 7.85(\mathrm{t}, J=7.7 \mathrm{~Hz}, 1 \mathrm{H}), 7.69$ (dd, $J=7.2,8.1 \mathrm{~Hz}, 1 \mathrm{H}), 4.22(\mathrm{~s}, 2 \mathrm{H}) .{ }^{13} \mathrm{C}-\mathrm{NMR}(125 \mathrm{MHz}$, $\left.\mathrm{CD}_{3} \mathrm{OD}\right): \delta$ (ppm) 185.92, 144.27, 136.81, 133.71, 133.67, $133.47,132.89,132.14,130.38,129.00,128.43,128.38(2 \mathrm{C})$, 51.10. FT-IR: $\nu\left(\mathrm{cm}^{-1}\right): 3054,3041$ (Aromatic CH st.), 1636, 1618, 1595, 1569, 1508 ( $\mathrm{C}=\mathrm{O}$ st., $\mathrm{C}=\mathrm{C}$ st., CCC b.), 1407, $1387,1359,1281,1256,1206,1171,1145,1120,1058,1041$, 1024 ( $\mathrm{C}=\mathrm{C}$ st., SO st., CH b., CCC b.), 925, 891, 844, 800, 771, 743, 633, 610 (Aromatic -CH opb.). MS: HRMS (ESI ${ }^{-}$), calcd for $\mathrm{C}_{14} \mathrm{H}_{9} \mathrm{O}_{4} \mathrm{~S}[\mathrm{M}]^{-}:$273.022703; found, 273.022380 . MW: $296.27 \mathrm{~g} / \mathrm{mol} . \mathrm{mp}>260{ }^{\circ} \mathrm{C}$.

2-(Thiocyanatomethyl)-1H-phenalen-1-one 9 (PNSCN). $\mathrm{PNCl}(228 \mathrm{mg}, 1 \mathrm{mmol})$ and $485 \mathrm{mg}(5 \mathrm{mmol})$ of potassium thiocyanate were dissolved in $62 \mathrm{~mL}$ of $\mathrm{MeOH}$ and stirred 48 $\mathrm{h}$ at room temperature. The solvent was evaporated, and the crude was purified by column chromatography (eluent: $\mathrm{CH}_{2} \mathrm{Cl}_{2} /$ petroleum ether 55:45) to yield $117 \mathrm{mg}(0.47$ mmol, $47 \%)$ of a bright yellow powder. ${ }^{1} \mathrm{H}-\mathrm{NMR}$ (500 $\left.\mathrm{MHz}, \mathrm{CDCl}_{3}\right): \delta(\mathrm{ppm}) 8.57(\mathrm{~d}, J=7.3 \mathrm{~Hz}, 1 \mathrm{H}), 8.50$ (d, $J=$ $8.0 \mathrm{~Hz}, 1 \mathrm{H}), 8.30(\mathrm{~d}, J=8.3 \mathrm{~Hz}, 1 \mathrm{H}), 8.20(\mathrm{~s}, 1 \mathrm{H}), 8.12(\mathrm{~d}, J$ $=7.0 \mathrm{~Hz}, 1 \mathrm{H}), 7.94(\mathrm{t}, J=7.7 \mathrm{~Hz}, 1 \mathrm{H}), 7.78(\mathrm{dd}, J=7.4,8 \mathrm{~Hz}$, $1 \mathrm{H}), 4.29$ (s, 2H). ${ }^{13} \mathrm{C}-\mathrm{NMR}\left(125 \mathrm{MHz}, \mathrm{CDCl}_{3}\right): \delta$ (ppm) 182.24, 141.49, 135.89, 133.29, 133.17, 132.81, 131.72, 130.48, $127.99,127.56,127.35,126.42,126.19,113.12,32.62$. FT-IR: $\nu\left(\mathrm{cm}^{-1}\right): 3000$ (Aromatic CH st.), 2150 (CN st.), 1638, 1622, 1594, 1568, 1507 ( $\mathrm{C}=\mathrm{O}$ st., $\mathrm{C}=\mathrm{C}$ st., CCC b.), 1404, 1389, $1358,1268,1257,1243,1227,1188,1177,1121$ (C=C st., $\mathrm{CH}$ b., CCC b.), 926, 890, 847, 785, 775, 745, 650 (Aromatic $-\mathrm{CH}$ opb.). MS: HRMS (ESI $\left.{ }^{+}\right)$, calcd for $\mathrm{C}_{15} \mathrm{H}_{10} \mathrm{NOS}[\mathrm{M}+$ $\mathrm{H}]^{+}$: 252.047761; found, 252.047774. MW: $251.3 \mathrm{~g} / \mathrm{mol} . \mathrm{mp}$ $135-140{ }^{\circ} \mathrm{C}$.

S-((1-oxo-1H-Phenalen-2-yl)methyl) Ethanethioate 10 (PNSAC). PNCl (1.03 g, $4.5 \mathrm{mmol})$ and $771 \mathrm{mg}(6.75$ $\mathrm{mmol}$ ) of potassium thioacetate were dissolved in $112 \mathrm{~mL}$ of $\mathrm{MeOH}$ and stirred for $4 \mathrm{~h}$ at room temperature under an inert atmosphere. Then, the precipitate was filtered off, and the filtrate was evaporated. The crude was purified by column chromatography (eluent: $\mathrm{CH}_{2} \mathrm{Cl}_{2}$ ) to yield $927 \mathrm{mg}(3.46$ mmol, 77\%) of a bright yellow powder. ${ }^{1} \mathrm{H}-\mathrm{NMR}(500 \mathrm{MHz}$, $\left.\mathrm{CDCl}_{3}\right): \delta(\mathrm{ppm}) 8.65(\mathrm{dd}, J=0.9,7.3 \mathrm{~Hz}, 1 \mathrm{H}), 8.20(\mathrm{~d}, J=$ $7.7 \mathrm{~Hz}, 1 \mathrm{H}), 8.00(\mathrm{~d}, J=8.2 \mathrm{~Hz}, 1 \mathrm{H}), 7.91(\mathrm{~s}, 1 \mathrm{H}), 7.79$ (d, $J$ $=7.5 \mathrm{~Hz}, 1 \mathrm{H}), 7.78(\mathrm{~d}, 7.3 \mathrm{~Hz}, 1 \mathrm{H}), 7.58(\mathrm{dd}, J=7.4,8.1 \mathrm{~Hz}$, $1 \mathrm{H}), 4.10(\mathrm{~s}, 2 \mathrm{H}), 2.33(\mathrm{~s}, 3 \mathrm{H}) .{ }^{13} \mathrm{C}-\mathrm{NMR}\left(125 \mathrm{MHz}, \mathrm{CDCl}_{3}\right)$ : $\delta(\mathrm{ppm}) 195.99,184.25,139.99,136.10,135.03,132.02$, 131.72, 131.70, 130.83, 129.07, 127.57, 127.20, 127.16, 126.78, 30.46, 28.46. FT-IR: $\nu\left(\mathrm{cm}^{-1}\right): 3049,2981$ (Aromatic CH st.), 1675 (CO thioester st.), 1640, 1623, 1597, 1570, 1507 (C=O st., $\mathrm{C}=\mathrm{C}$ st., $\mathrm{CCC}$ b.), 1401, 1388, 1351, 1246, 1253, 1185, 1134, 1102, 1037, 1022, 1003 (C=C st., CH b., CCC b.), 957, 943, 872, 846, 795, 781, 708, 687, 626 (Aromatic - $\mathrm{CH}$ opb., CS st.). MS: HRMS (ESI ${ }^{+}$, calcd for $\mathrm{C}_{16} \mathrm{H}_{13} \mathrm{O}_{2} \mathrm{~S}[\mathrm{M}+\mathrm{H}]^{+}$: 269.063077; found, 269.063190. MW: $268.33 \mathrm{~g} / \mathrm{mol}$. mp 105 ${ }^{\circ} \mathrm{C}$.

2-(Mercaptomethyl)-1H-phenalen-1-one 11 (PNSH). In $100 \mathrm{~mL}$ of argon-purged methanol containing $532 \mathrm{mg}(2$ mmol) of PNSAc was added $1.1 \mathrm{~g}(8 \mathrm{mmol})$ of $\mathrm{K}_{2} \mathrm{CO}_{3}$, and the reaction was kept for $3 \mathrm{~h}$ under stirring at room temperature. The solution slowly turned orange. After completion of the reaction, a solution of argon-purged $\mathrm{HCl}$ / methanol was added until the solution turned back to yellow. The solvent was evaporated, and the crude was purified by column chromatography to yield $347 \mathrm{mg}$ (1.53 mmol, 77\%) of 
a yellow powder. The compound was stored under argon at $-22{ }^{\circ} \mathrm{C}$ to prevent thiol oxidation. ${ }^{1} \mathrm{H}-\mathrm{NMR}(500 \mathrm{MHz}$, $\left.\mathrm{CDCl}_{3}\right): 8.67(\mathrm{~d}, J=7.4 \mathrm{~Hz}, 1 \mathrm{H}), 8.21(\mathrm{~d}, J=8.1,1 \mathrm{H}), 8.01$ $(\mathrm{d}, J=8.3 \mathrm{~Hz}, 1 \mathrm{H}), 7.78(\mathrm{~m}, 3 \mathrm{H}), 7.60(\mathrm{dd}, J=7.3,8.0 \mathrm{~Hz}$, $1 \mathrm{H}), 3.75(\mathrm{~d}, J=8.3 \mathrm{~Hz}, 2 \mathrm{H}), 2.12(\mathrm{t}, J=8.3 \mathrm{~Hz}, 1 \mathrm{H}) .{ }^{13} \mathrm{C}-$ NMR (125 MHz, $\mathrm{CDCl}_{3}$ ): 184.11, 139.37, 138.47, 134.99, 132.03, 131.58, 131.29, 130.80, 129.20, 127.65, 127.20, 127.13, 126.77, 24.00. FT-IR: $\nu\left(\mathrm{cm}^{-1}\right): 3047,2931,2856$ (Aromatic CH st.), 2581 (SH st.), 1634, 1619, 1594, 1579, 1567, 1506 (C=O st., $\mathrm{C}=\mathrm{C}$ st., CCC b.), 1403, 1391, 1358, 1249, 1191, 1125, 1039, 1026 (C=C st., CH b., CCC b.), 973, 943, 846, 788, 767, 696, 681 (Aromatic -CH opb., CS st.). MS: HRMS $\left(\mathrm{ESI}^{+}\right)$, calcd for $\mathrm{C}_{14} \mathrm{H}_{11} \mathrm{OS}[\mathrm{M}+\mathrm{H}]^{+}$: 227.052512; found, 227.052037. MW: $226.29 \mathrm{~g} / \mathrm{mol}$. mp $95{ }^{\circ} \mathrm{C}$.

Methyl 1-((1-oxo-1H-Phenalen-2-yl)methyl)-1H-1,2,3-triazole-4-carboxylate 12 (PNCOOMe). $\mathrm{PNN}_{3}$ (299 mg, 1.27 $\mathrm{mmol}), 115 \mu \mathrm{L}$ (1.28 mmol) of methyl propiolate, $7.6 \mathrm{mg}$ (40 $\mu \mathrm{mol})$ of copper(I) iodide, $14 \mu \mathrm{L}(80 \mu \mathrm{mol})$ of diisopropylethylamine, and $4.6 \mu \mathrm{L}(80 \mu \mathrm{mol})$ of glacial acetic acid were dissolved in $4 \mathrm{~mL}$ of $\mathrm{CH}_{2} \mathrm{Cl}_{2}$ and stirred $90 \mathrm{~min}$ at room temperature. The translucent solution turned bright yellow. The formed precipitate was dissolved and purified on a short column to yield $401 \mathrm{mg}(1.26 \mathrm{mmol}, 99 \%)$ of a bright yellow powder. ${ }^{1} \mathrm{H}-\mathrm{NMR}\left(500 \mathrm{MHz}, \mathrm{CDCl}_{3}\right): \delta(\mathrm{ppm}) 8.68$ (dd, $J=$ $0.9,7.4 \mathrm{~Hz}, 1 \mathrm{H}), 8.41(\mathrm{~s}, 1 \mathrm{H}), 8.25(\mathrm{~d}, J=7.8 \mathrm{~Hz}, 1 \mathrm{H}), 8.09$ $(\mathrm{d}, J=8.3 \mathrm{~Hz}, 1 \mathrm{H}), 7.63(\mathrm{~m}, 3 \mathrm{H}), 7.63(\mathrm{dd}, J=7.3,8.1 \mathrm{~Hz}$, $1 \mathrm{H}), 5.62(\mathrm{~s}, 2 \mathrm{H}), 3.93(\mathrm{~s}, 3 \mathrm{H}) .{ }^{13} \mathrm{C}-\mathrm{NMR}(125 \mathrm{MHz}$, $\left.\mathrm{CDCl}_{3}\right): \delta(\mathrm{ppm})$ 183.87, 161.22, 142.02, 140.10, 135.79, 133.08, 133.03, 132.76, 132.14, 131.29, 128.91, 128.83, 127.52, 127.47, 127.03, 126.69, 52.18, 49.52. FT-IR: $\nu\left(\mathrm{cm}^{-1}\right): 3128$ $\left(\mathrm{CH}_{3}\right.$ st.), 3053, 2953 (Aromatic CH st.), 1737 ( $\mathrm{C}=\mathrm{O}$ ester st.), 1640, 1618, 1601, 1568, 1534 ( $\mathrm{C}=\mathrm{O}$ st., $\mathrm{C}=\mathrm{C}$ st., CCC b.), 1439, 1405, 1395, 1363, 1268, 1248, 1204, 1149, 1126, 1114, 1051, 1016 ( $\mathrm{C}=\mathrm{C}$ st., CO st., CH b., CCC b.), 946, 918, 887, 845, 780, 696, 653 (Aromatic -CH opb.). MS: HRMS $\left(\right.$ ESI $\left.^{+}\right)$, calcd for $\mathrm{C}_{18} \mathrm{H}_{14} \mathrm{~N}_{3} \mathrm{O}_{3}[\mathrm{M}+\mathrm{H}]^{+}$: 320.102968 ; found; 320.103102 . MW: $319.32 \mathrm{~g} / \mathrm{mol} . \mathrm{mp} 207{ }^{\circ} \mathrm{C}$.

4-Carboxy-1-((1-oxo-1H-phenalen-2-yl)methyl)- $1 \mathrm{H}-1,2,3-$ triazol-1-ium chloride 13 (PNCOOH-A). PNCOOMe (700 $\mathrm{mg}, 2.19 \mathrm{mmol}$ ) was dissolved in $40 \mathrm{~mL}$ of $37 \% \mathrm{HCl}$ in dioxane $(1: 1 \mathrm{v} / \mathrm{v})$ and stirred $4 \mathrm{~h}$ at $70{ }^{\circ} \mathrm{C}$. Then, the solution was poured into $500 \mathrm{~mL}$ of cold water, and the yellow precipitate was filtered. The solid was dissolved in $\mathrm{CHCl}_{3}$ / $\mathrm{MeOH}$ 90:10 and dried over $\mathrm{MgSO}_{4}$, and the solvent was evaporated to yield $677 \mathrm{mg}(1.98 \mathrm{mmol}, 90 \%)$ of a bright yellow powder. ${ }^{1} \mathrm{H}-\mathrm{NMR}\left(500 \mathrm{MHz}, \mathrm{DMSO}-d_{6}\right): \delta(\mathrm{ppm})$ $8.75(\mathrm{~s}, 1 \mathrm{H}), 8.51(\mathrm{~d}, J=7.3 \mathrm{~Hz}, 1 \mathrm{H}), 8.47(\mathrm{~d}, J=8.0 \mathrm{~Hz}$, $1 \mathrm{H}), 8.27$ (d, $J=8.2 \mathrm{~Hz}, 1 \mathrm{H}), 8.07(\mathrm{~d}, J=7.0 \mathrm{~Hz}, 1 \mathrm{H}), 7.93$ $(\mathrm{s}, 1 \mathrm{H}), 7.91(\mathrm{t}, J=7.7 \mathrm{~Hz}, 1 \mathrm{H}), 7.74(\mathrm{t}, J=7.6 \mathrm{~Hz}, 1 \mathrm{H}), 5.61$ (s, 2H). ${ }^{13} \mathrm{C}-\mathrm{NMR}\left(125 \mathrm{MHz}, \mathrm{DMSO}-d_{6}\right): \delta$ (ppm) 182.78, 161.65, 141.11, 139.59, 135.83, 133.18, 132.88, 132.71, 131.67, $130.30,129.65,128.11,127.51,127.30,126.39,126.29,48.81$. FT-IR: $\nu\left(\mathrm{cm}^{-1}\right): 3357$ (OH st.), 2605, 2522 (Aromatic CH st.), 1701 ( $\mathrm{C}=\mathrm{O}$ acid st.), 1639, 1619, 1597, 1568, 1549, 1510 ( $\mathrm{C}=\mathrm{O}$ st., $\mathrm{C}=\mathrm{C}$ st., $\mathrm{CCC}$ b. $), 1426,1403,1364,1338,1268$, $1253,1225,1188,1147,1125,1098,1055,1016$ ( $\mathrm{C}=\mathrm{C}$ st., CO st., CH b., CCC b.), 937, 849, 804, 795, 782, 771, 753, 717, 700 (Aromatic - CH opb.). MS: HRMS (ESI ${ }^{+}$), calcd for $\mathrm{C}_{17} \mathrm{H}_{12} \mathrm{~N}_{3} \mathrm{O}_{3}[\mathrm{M}+\mathrm{H}]^{+}$: 306.087318; found, 306.087284. MW: $341.75 \mathrm{~g} / \mathrm{mol} . \mathrm{mp} 140{ }^{\circ} \mathrm{C}$ (degradation).

9-(1-((1-oxo-1H-Phenalen-2-yl)methyl)-1H-1,2,3-triazol-4yl)nonanoic acid 14 (PNCOOH-B). $\mathrm{PNN}_{3}$ (118 mg, 0.5 $\mathrm{mmol}), 91 \mathrm{mg}(0.5 \mathrm{mmol})$ of 10-undecynoic acid, $19.6 \mathrm{mg}$ of sodium ascorbate, and $2.5 \mathrm{mg}$ of copper(II) sulfate pentahydrate were dissolved in $100 \mathrm{~mL}$ of a $\mathrm{MeOH} / \mathrm{H}_{2} \mathrm{O}$ (4:1) mixture and stirred $48 \mathrm{~h}$ at room temperature. The solvents were then evaporated, and the crude was purified by column chromatography (eluent: $\mathrm{CH}_{2} \mathrm{Cl}_{2} / \mathrm{EP} 1: 1$ ) to yield 121 $\mathrm{mg}(0.29 \mathrm{mmol}, 58 \%)$ of a poorly soluble yellow powder. ${ }^{1} \mathrm{H}$ NMR $\left(500 \mathrm{MHz}, \mathrm{DMSO}-d_{6}\right): \delta(\mathrm{ppm}) 8.53(\mathrm{dd}, J=0.8,7.5$ $\mathrm{Hz}, 1 \mathrm{H}), 8.47(\mathrm{~d}, J=7.8 \mathrm{~Hz}, 1 \mathrm{H}), 8.26(\mathrm{~d}, J=8.2 \mathrm{~Hz}, 1 \mathrm{H})$, $8.03(\mathrm{~d}, J=6.9 \mathrm{~Hz}, 1 \mathrm{H}), 7.92(\mathrm{~d}, J=8.0 \mathrm{~Hz}, 1 \mathrm{H}), 7.90(\mathrm{~d}, J=$ $7.4 \mathrm{~Hz}, 1 \mathrm{H}), 7.82(\mathrm{~s}, 1 \mathrm{H}), 7.73(\mathrm{dd}, J=7.4,8.0 \mathrm{~Hz}, 1 \mathrm{H}), 5.49$ $(\mathrm{s}, 2 \mathrm{H}), 2.60(\mathrm{t}, J=7.6 \mathrm{~Hz}, 2 \mathrm{H}), 2.09(\mathrm{~m}, 2 \mathrm{H}), 1.56(\mathrm{q}, J=7.5$ $\mathrm{Hz}, 2 \mathrm{H}), 1.44(\mathrm{t}, J=6.5 \mathrm{~Hz}, 2 \mathrm{H}), 1.23(\mathrm{~m}, 8 \mathrm{H}) .{ }^{13} \mathrm{C}-\mathrm{NMR}$ $\left(125 \mathrm{MHz}, \mathrm{DMSO}-d_{6}\right): \delta(\mathrm{ppm}) 182.72,175.14,146.88$, $140.50,135.68,133.60,132.85,132.48,131.61,130.19,128.09$, $127.44,127.22,126.28,122.32,48.02,34.64,28.83,28.67$, $28.63,28.58,28.48,24.93,24.85$. FT-IR: $\nu\left(\mathrm{cm}^{-1}\right): 2929$, 2912, 2849 (Aromatic CH st.), 1695 (C=O acid st.), 1642, 1631, 1602, 1574, 1549 (C=O st., C=C st., CCC b.), 1469, 1431 (1,2,3 triazole ring st.), 1395, 1362, 1327, 1266, 1251, 1209, 1191, 1056, 1014 (C=C st., CH b., CCC b.), 919, 891, 844, 780, 770, 724, 680, 650 (Aromatic -CH opb.). MS: HRMS $\left(\mathrm{ESI}^{+}\right.$), calcd for $\mathrm{C}_{25} \mathrm{H}_{28} \mathrm{~N}_{3} \mathrm{O}_{3}[\mathrm{M}+\mathrm{H}]^{+}$: 418.212518; found, 418.212673. MW: $417.21 \mathrm{~g} / \mathrm{mol}$. mp $145{ }^{\circ} \mathrm{C}$.

tert-Butyl ((1-((1-oxo-1H-Phenalen-2-yl)methyl)-1H-1,2,3triazol-4-yl)methyl)carbamate 15 (PNBOC). $\mathrm{PNN}_{3}$ (1.45 g, $6.16 \mathrm{mmol}), 1.25 \mathrm{~g}(6.47 \mathrm{mmol})$ of N-BOC-propargylamine, $38 \mathrm{mg}(0.123 \mathrm{mmol})$ of CuI, $70 \mu \mathrm{L}(0.123 \mathrm{mmol})$ of DIPEA, and $22.8 \mu \mathrm{L}(0.246 \mathrm{mmol})$ of acetic acid were placed in an erlenmeyer with the minimum volume of $\mathrm{CH}_{2} \mathrm{Cl}_{2}(\sim 20 \mathrm{~mL})$. The reaction was left for $20 \mathrm{~min}$ at room temperature under stirring until a deep yellow solid appeared. The crude was evaporated and purified by column chromatography $\left(\mathrm{CHCl}_{3} /\right.$ $\mathrm{MeOH} \mathrm{9:1)} \mathrm{to} \mathrm{yield} 2.40 \mathrm{~g}(6.15 \mathrm{mmol}, 99 \%)$ of a yellow powder. ${ }^{1} \mathrm{H}-\mathrm{NMR}\left(500 \mathrm{MHz}, \mathrm{CDCl}_{3}\right): 8.67(\mathrm{dd}, J=0.8,7.4$ $\mathrm{Hz}, 1 \mathrm{H}), 8.24(\mathrm{~d}, J=8.0 \mathrm{~Hz}, 1 \mathrm{H}), 8.06(\mathrm{~d}, J=8.3 \mathrm{~Hz}, 1 \mathrm{H})$, $7.82(\mathrm{t}, J=7.7 \mathrm{~Hz}, 1 \mathrm{H}), 7.77(\mathrm{~m}, 2 \mathrm{H}), 7.70(\mathrm{~s}, 1 \mathrm{H}), 7.62(\mathrm{dd}$, $J=7.3,8.0 \mathrm{~Hz}, 1 \mathrm{H}), 5.55(\mathrm{~s}, 2 \mathrm{H}), 5.08(\mathrm{~s}, 1 \mathrm{H}), 4.41(\mathrm{~d}, J=5.4$ $\mathrm{Hz}, 2 \mathrm{H}), 1.42$ (s, 9H). ${ }^{13} \mathrm{C}-\mathrm{NMR}\left(125 \mathrm{MHz}, \mathrm{CDCl}_{3}\right): 183.83$, $155.77,145.55,141.10,135.55,133.52,132.68,132.65,132.05$, $131.08,128.84,127.37,127.34,126.90,126.82,122.96,79.65$, 48.91, 36.29, 28.38 (3C). -FT-IR: $\nu\left(\mathrm{cm}^{-1}\right): 3350$ (NH st.), 3141, 2972 (Aromatic CH st.), 1687 (CO amide st.), 1641, $1622,1600,1570$ ( $\mathrm{C}=\mathrm{O}$ st., $\mathrm{C}=\mathrm{C}$ st., $\mathrm{CCC}$ b.), 1529 ( $\mathrm{CN}$ st., $\mathrm{NH}$ b.), 1404 (1,2,3-triazole ring st.), 1395, 1359, 1320, $1265,1249,1168,1127,1054,1026,1013$ (C=C st., $\mathrm{CH}$ b., CCC b.), 963, 930, 918, 881, 864, 844, 802, 779, 769, 653 (Aromatic - $\mathrm{CH}$ opb.). MS: HRMS $\left(\mathrm{ESI}^{+}\right)$, calcd for $\mathrm{C}_{22} \mathrm{H}_{23} \mathrm{~N}_{4} \mathrm{O}_{3}[\mathrm{M}+\mathrm{H}]^{+}$: 391.176467; found, 391.176309 . MW: $390.44 \mathrm{~g} / \mathrm{mol} . \mathrm{mp} 174{ }^{\circ} \mathrm{C}$.

4-(Ammoniomethyl)-1-((1-oxo-1H-Phenalen-2-yl)methyl)-1H-1,2,3-triazol-1-ium chloride 16 (PNNH2-A). PNBOC (462 mg, $1.18 \mathrm{mmol}$ ) was dissolved in $20 \mathrm{~mL}$ of $37 \% \mathrm{HCl} /$ dioxane $(3: 1)$ and left under stirring at room temperature for $2 \mathrm{~h}$. Solvent and acid were then evaporated, and the crude was solubilized in a minimum of methanol. A large volume of diethyl ether was added, causing the formation of a yellow precipitate. The solid was filtered and dried under vacuum to obtain a yellow powder with a quantitative yield (428 mg, $1.18 \mathrm{mmol}$ ). ${ }^{1} \mathrm{H}-\mathrm{NMR}\left(500 \mathrm{MHz}, \mathrm{D}_{2} \mathrm{O}\right.$ ): 8.26 (s, $1 \mathrm{H}), 7.75(\mathrm{dd}, J=1.0,7.5 \mathrm{~Hz}, 1 \mathrm{H}), 7.74(\mathrm{~d}, J=8.0 \mathrm{~Hz}, 1 \mathrm{H})$, $7.63(\mathrm{~d}, J=8.0 \mathrm{~Hz}, 1 \mathrm{H}), 7,38(\mathrm{~s}, 1 \mathrm{H}), 7.34(\mathrm{~d}, J=7.4 \mathrm{~Hz}$, $1 \mathrm{H}), 7.28(\mathrm{t}, J=7.6 \mathrm{~Hz}, 1 \mathrm{H}), 7.25(\mathrm{dd}, J=7.2,0.8 \mathrm{~Hz}, 1 \mathrm{H})$, $5.30(\mathrm{~s}, 2 \mathrm{H}), 4.44(\mathrm{~s}, 2 \mathrm{H}) .{ }^{13} \mathrm{C}-\mathrm{NMR}\left(125 \mathrm{MHz}, \mathrm{D}_{2} \mathrm{O}\right)$ : 
$184.39,143.26,139.65,136.48,134.14,133.62,130.82,130.70$, 130.67, 126.87, 126.78, 126.60, 126.18, 125.07, 125.00, 49.48, 34.04. FT-IR: $\nu\left(\mathrm{cm}^{-1}\right): 3410(\mathrm{NH}$ st.), 2923 (Aromatic CH St.), 1637, 1618, 1596, 1567, 1508 (C=O st., C=C st., CCC b.), 1404 (1,2,3 triazole ring st.), 1361, 1253, 1226, 1125, 1053 971 ( $\mathrm{C}=\mathrm{C}$ st., $\mathrm{CH}$ b., CCC b.), 885, 806, 774 (Aromatic $-\mathrm{CH}$ opb.). MS: HRMS (ESI ${ }^{+}$), calcd for $\mathrm{C}_{17} \mathrm{H}_{15} \mathrm{~N}_{4} \mathrm{O}[\mathrm{M}-$ $\mathrm{H}]^{+}$: 291.123866; found, 291.124038. MW: $363.24 \mathrm{~g} / \mathrm{mol}$. mp $151{ }^{\circ} \mathrm{C}$ (degradation).

(1-oxo-1H-Phenalen-2-yl)methanaminium chloride 17 (PNNH2-B). $\mathrm{PNN}_{3}$ (1.05 g, $\left.4.45 \mathrm{mmol}\right)$ and $1.34 \mathrm{~g}$ (5.12 mmol) of triphenylphosphine were dissolved in $215 \mathrm{~mL}$ of $\mathrm{THF}$, and $256 \mu \mathrm{L}$ of water was added. The solution was stirred for $12 \mathrm{~h}$ at $70{ }^{\circ} \mathrm{C}$. The solvent was evaporated, and the crude was purified by column chromatography. The viscous oil obtained was protonated with $3 \mathrm{~mL}$ of $37 \% \mathrm{HCl}$, evaporated, and crystallized in petroleum ether to yield $1.02 \mathrm{~g}(4.15 \mathrm{mmol}$, 93\%) of a matt yellow powder (litt.: $\left.46 \%{ }^{11}\right)$. ${ }^{1} \mathrm{H}-\mathrm{NMR}(500$ $\left.\mathrm{MHz}, \mathrm{CD}_{3} \mathrm{OD}\right): \delta(\mathrm{ppm}) 8.66(\mathrm{dd}, J=1.1,7.4 \mathrm{~Hz}, 1 \mathrm{H}), 8.41$ $(\mathrm{dd}, J=0.8,8.1 \mathrm{~Hz}, 1 \mathrm{H}), 8.24(\mathrm{~d}, J=8.3 \mathrm{~Hz}, 1 \mathrm{H}), 8.13(\mathrm{~s}$, $1 \mathrm{H}), 8.03(\mathrm{~d}, J=6.7 \mathrm{~Hz}, 1 \mathrm{H}), 7.90(\mathrm{t}, J=7.7 \mathrm{~Hz}, 1 \mathrm{H}), 7.74$ $(\mathrm{dd}, J=7.1,8.2 \mathrm{~Hz}, 1 \mathrm{H}), 4.14(\mathrm{~s}, 2 \mathrm{H}) .{ }^{13} \mathrm{C}-\mathrm{NMR}(125 \mathrm{MHz}$, $\left.\mathrm{CD}_{3} \mathrm{OD}\right): \delta(\mathrm{ppm}) 185.91,144.40,137.54,134.90,134.71$, 133.79, 132.43, 132.19, 129.89, 128.77, 128.60, 128.54, 127.98, 40.77. FT-IR: $\nu\left(\mathrm{cm}^{-1}\right): 3374(\mathrm{NH}$ st.), 2812 (Aromatic $\mathrm{CH}$ st.), $1636,1561,1508$ ( $\mathrm{C}=\mathrm{O}$ st., $\mathrm{C}=\mathrm{C}$ st., $\mathrm{CCC}$ b. $), 1472$, $1439,1400,1376,1257,1228,1121,1022,962$ (C=C st., $\mathrm{CH}$ b., CCC b.), 911, 845, 784, 765, 724, 694 (Aromatic $-\mathrm{CH}$ opb.). MS: HRMS (ESI+), calcd for $\mathrm{C}_{14} \mathrm{H}_{12} \mathrm{NO}[\mathrm{M}+\mathrm{H}]^{+}$: 210.091340; found, 210.091153. MW: $245.5 \mathrm{~g} / \mathrm{mol}$. mp 210 ${ }^{\circ} \mathrm{C}$ (degradation).

(3r,5r,7r)-N-((1-((1-oxo-1H-Phenalen-2-yl)methyl)-1H1,2,3-triazol-4-yl)methyl)adamantane-1-carboxamide 18 (PNAda). PNNH2-B (121 mg, $0.33 \mathrm{mmol})$ was dissolved in a $\mathrm{CH}_{2} \mathrm{Cl}_{2}$ /DIPEA (2:1) mixture under an inert atmosphere, and $67 \mathrm{mg}(0.33 \mathrm{mmol})$ of 1-adamantanecarbonyl chloride was slowly added. The reaction was left for $5 \mathrm{~min}$ at room temperature, and the solvents were distilled under reduced pressure. The crude was purified by column chromatography $\left(\mathrm{CHCl}_{3} / \mathrm{MeOH} 99: 1\right)$ to yield $87 \mathrm{mg}(0.19 \mathrm{mmol}, 58 \%)$ of a yellow powder. ${ }^{1} \mathrm{H}-\mathrm{NMR}\left(500 \mathrm{MHz}, \mathrm{CDCl}_{3}\right): \delta(\mathrm{ppm}) 8.67$ $(\mathrm{dd}, J=1.0,7.4 \mathrm{~Hz}, 1 \mathrm{H}), 8.24(\mathrm{~d}, J=8.1 \mathrm{~Hz}, 1 \mathrm{H}), 8.07(\mathrm{~d}, J=$ $8.3 \mathrm{~Hz}, 1 \mathrm{H}), 7.82$ (t, $J=7.7 \mathrm{~Hz}, 1 \mathrm{H}), 7.77(\mathrm{~d}, J=7.6 \mathrm{~Hz}, 1 \mathrm{H})$, $7.76(\mathrm{~s}, 1 \mathrm{H}), 7.68(\mathrm{~s}, 1 \mathrm{H}), 7.62(\mathrm{dd}, J=7.2,8.1 \mathrm{~Hz}, 1 \mathrm{H}), 6.28$ $(\mathrm{t}, J=4.8 \mathrm{~Hz}, 1 \mathrm{H}), 5.55(\mathrm{~s}, 2 \mathrm{H}), 4.5(\mathrm{~d}, J=5.4 \mathrm{~Hz}, 2 \mathrm{H}), 2.01$ $(\mathrm{m}, 3 \mathrm{H}), 1.84(\mathrm{~m}, 6 \mathrm{H}), 1.70(\mathrm{~m}, 6 \mathrm{H}) .{ }^{13} \mathrm{C}-\mathrm{NMR}(125 \mathrm{MHz}$, $\left.\mathrm{CDCl}_{3}\right): \delta(\mathrm{ppm}) 183.79,177.98,144.99,141.08,135.55$, $133.47,132.70,132.63,132.05,131.10,128.83,127.40,127.34$, $126.89,126.82,123.19,48.96,40.60,39.15$ (3C), 36.50 (3C), 34.99, 28.10 (3C). FT-IR: $\nu\left(\mathrm{cm}^{-1}\right): 2903,2849$ (Aromatic $\mathrm{CH}$ st.), 1640, 1598, 1572, 1510 ( $\mathrm{C}=\mathrm{O}$ st., $\mathrm{C}=\mathrm{C}$ st., CCC b.), 1452, 1405 (1,2,3-triazole ring st.), 1362, 1254, 1183, 1104, 1049 (C=C st., CH b., CCC b.), 812, 778, 662 (Aromatic - $\mathrm{CH}$ opb.). MS: HRMS $\left(\mathrm{ESI}^{+}\right)$, calcd for $\mathrm{C}_{28} \mathrm{H}_{29} \mathrm{~N}_{4} \mathrm{O}_{2} \quad[\mathrm{M}+\mathrm{H}]^{+}:$453.228503; found, 453.228830 . MW: $452.56 \mathrm{~g} / \mathrm{mol} . \mathrm{mp} 51{ }^{\circ} \mathrm{C}$ (degradation).

6-(2,5-Dioxo-2,5-dihydro-1H-pyrrol-1-yl)-N-((1-oxo-1Hphenalen-2-yl)methyl)hexanamide 19 (PNMal). 6-Maleimidohexanoic acid (682 $\mathrm{mg}, 3.23 \mathrm{mmol}), 555 \mathrm{mg}(4.84 \mathrm{mmol})$ of $\mathrm{N}$-hydroxysuccinimide, and $799 \mathrm{mg}(3.88 \mathrm{mmol})$ of dicyclohexylcarbodiimide were dissolved in $20 \mathrm{~mL}$ of anhydrous DMF under an inert atmosphere and left to react overnight. The dicyclohexylurea crystals were then discarded, and $660 \mathrm{mg}(2.65 \mathrm{mmol})$ of PNNH2-B and $738 \mu \mathrm{L}(5.3$ $\mathrm{mmol}$ ) of triethylamine were dissolved in $20 \mathrm{~mL}$ of anhydrous DMF, and the mixture was added slowly to the reaction. The whole was left for $18 \mathrm{~h}$ under an inert atmosphere at room temperature. The solvents were evaporated, the crude was dissolved in $\mathrm{CH}_{2} \mathrm{Cl}_{2}$, and the solid was filtered off. The filtrate was evaporated and purified by column chromatography (eluent: $\left.\mathrm{CHCl}_{3} / \mathrm{MeOH} 98: 2\right)$ to yield $970 \mathrm{mg}(2.41 \mathrm{mmol}$, $91 \%)$ of a yellow powder. ${ }^{1} \mathrm{H}-\mathrm{NMR}\left(500 \mathrm{MHz}, \mathrm{CDCl}_{3}\right): \delta$ (ppm) $8.65(\mathrm{dd}, J=1.0,7.4 \mathrm{~Hz}, 1 \mathrm{H}), 8.23(\mathrm{dd}, J=0.8,8.0 \mathrm{~Hz}$, $1 \mathrm{H}), 8.03(\mathrm{~d}, J=8.2 \mathrm{~Hz}, 1 \mathrm{H}), 7.82(\mathrm{~s}, 1 \mathrm{H}), 7.81(\mathrm{t}, J=7.7 \mathrm{~Hz}$, $1 \mathrm{H}), 7.80(\mathrm{~d}, J=6.8 \mathrm{~Hz}, 1 \mathrm{H}), 7.62(\mathrm{dd}, J=7.3,8.2 \mathrm{~Hz}, 1 \mathrm{H})$, $6.63(\mathrm{~s}, 2 \mathrm{H}), 6.43(\mathrm{t}, J=5.6 \mathrm{H}, 1 \mathrm{H}), 4.41(\mathrm{~d}, J=6.2 \mathrm{~Hz}, 2 \mathrm{H})$, $3.47(\mathrm{t}, J=7.3 \mathrm{~Hz}, 2 \mathrm{H}), 2.18(\mathrm{t}, J=7.6 \mathrm{~Hz}, 2 \mathrm{H}), 1.66\left(\mathrm{q}^{5}, J=\right.$ $7.6 \mathrm{~Hz}, 2 \mathrm{H}), 1.60(\mathrm{q} 5, J=7.5 \mathrm{~Hz}, 2 \mathrm{H}), 1.30(\mathrm{~m}, 2 \mathrm{H}) .{ }^{13} \mathrm{C}-$ NMR (125 MHz, $\left.\mathrm{CDCl}_{3}\right): \delta(\mathrm{ppm}) 185.71,172.67,170.79$ (2C), 140.10, 135.96, 135.27, 134.01 (2C), 132.10, 132.05, $131.87,130.62,129.19,127.48,127.23,127.14,126.90,49.19$, 37.63, 36.52, 28.26, 26.36, 25.04. FT-IR: $\nu\left(\mathrm{cm}^{-1}\right): 3276(\mathrm{NH}$ st.), 2936 (Aromatic CH st.), 1697 ( $\mathrm{C}=\mathrm{O}$ maleimide st.), 16301568 ( $\mathrm{C}=\mathrm{O}$ st., $\mathrm{C}=\mathrm{C}$ st., CCC b.), 1405 (C,C > N symmetric st.), 1362, 1248, 1225, 1131, 1047, (C=C st., $\mathrm{CH}$ b., CCC b.), 827, 810, 778 (Aromatic-CH opb.), 695 (ring bending maleimide). MS: HRMS $\left(\mathrm{ESI}^{+}\right)$, calcd for $\mathrm{C}_{24} \mathrm{H}_{23} \mathrm{~N}_{2} \mathrm{O}_{4}[\mathrm{M}+\mathrm{H}]^{+}$: 403.165234; found, 403.165045 . MW: $402.45 \mathrm{~g} / \mathrm{mol} . \mathrm{mp} 148{ }^{\circ} \mathrm{C}$.

(2R,3R,4S,5R,6R)-2-(Acetoxymethyl)-6-((1-((1-oxo-1H-phenalen-2-yl)methyl)-1H-1,2,3-triazol-4-yl)methoxy)tetrahydro-2H-pyran-3,4,5-triyl Triacetate 20 (PNGIc-A). $\mathrm{PNN}_{3}$ (235 mg, $\left.1 \mathrm{mmol}\right), 380 \mathrm{mg}(0.99 \mathrm{mmol})$ of 2 propynyl-tetra- $O$-acetyl- $\beta$-D-glucopyranoside, $3.8 \mathrm{mg}(0.02$ $\mathrm{mmol})$ of copper(I) iodide, $7 \mu \mathrm{L}(0.04 \mathrm{mmol})$ of diisopropylethylamine, and $2.4 \mu \mathrm{L}(0.04 \mathrm{mmol})$ of glacial acetic acid were dissolved in $10 \mathrm{~mL}$ of $\mathrm{CH}_{2} \mathrm{Cl}_{2}$ and stirred $72 \mathrm{~h}$ at room temperature. The solvent was evaporated, and the crude was purified by column chromatography (eluent: $\left.\mathrm{CHCl}_{3} / \mathrm{MeOH} 99: 1\right)$ to yield $444 \mathrm{mg}(0.71 \mathrm{mmol}, 72 \%)$ of a bright yellow powder. ${ }^{1} \mathrm{H}-\mathrm{NMR}\left(500 \mathrm{MHz}\right.$, acetone- $\left.d_{6}\right): \delta$ (ppm) $8.60(\mathrm{dd}, J=1.0,7.4 \mathrm{~Hz}, 1 \mathrm{H}), 8.43(\mathrm{~d}, J=8.1 \mathrm{~Hz}, 1 \mathrm{H})$, $8.24(\mathrm{~d}, J=8.3 \mathrm{~Hz}, 1 \mathrm{H}), 8.09(\mathrm{~s}, 1 \mathrm{H}), 8.01(\mathrm{~d}, J=7.3 \mathrm{~Hz}$, $1 \mathrm{H}), 7.91(\mathrm{t}, J=7.6 \mathrm{~Hz}, 1 \mathrm{H}), 7.81(\mathrm{~s}, 1 \mathrm{H}), 7.73(\mathrm{dd}, J=7.3$ et $8.2 \mathrm{~Hz}, 1 \mathrm{H}), 5.60(\mathrm{~s}, 2 \mathrm{H}), 5.26(\mathrm{t}, J=9.9 \mathrm{~Hz}, 1 \mathrm{H}), 5.05(\mathrm{dd}, J$ $=9.4,9.9 \mathrm{~Hz}, 1 \mathrm{H}), 4.92(\mathrm{dd}, J=8.1,9.4 \mathrm{~Hz}, 1 \mathrm{H}), 4.90(\mathrm{~d}, J=$ $12.6 \mathrm{~Hz}, 1 \mathrm{H}), 4.86(\mathrm{~d}, J=8.1 \mathrm{~Hz}, 1 \mathrm{H}), 4.81$ (d, $J=12.6 \mathrm{~Hz}$, $1 \mathrm{H}), 4.28$ (dd, $J=5.0,12.4 \mathrm{~Hz}, 1 \mathrm{H}), 4.15$ (dd, $J=2.4,12.3$ $\mathrm{Hz}, 1 \mathrm{H}), 3.97$ (ddd, $J=2.5,5.0,10.0 \mathrm{~Hz}, 1 \mathrm{H}), 2.02(\mathrm{~s}, 3 \mathrm{H})$, 1.98 (s, 3H), $1.92(\mathrm{~s}, 3 \mathrm{H}), 1.84(\mathrm{~s}, 3 \mathrm{H}) .{ }^{13} \mathrm{C}-\mathrm{NMR}(125 \mathrm{MHz}$, acetone- $\left.d_{6}\right): 184.10,170.81,170.36,170.08,169.72,144.68$, $141.50,136.50,135.12,133.75,133.45,133.27,131.25,129.80$, $128.40,128.22,128.06,127.95,125.52,100.14,73.61,72.57$, 72.18, 69.54, 63.17, 62.83, 49.63, 20.72, 20.68, 20.62, 20.62. FT-IR: $\nu\left(\mathrm{cm}^{-1}\right): 2954$ (Aromatic CH st.), 1751 ( $\mathrm{C}=\mathrm{O}$ acetyl st.), 1641, 1626, 1599, 1573 ( $\mathrm{C}=\mathrm{O}$ st., $\mathrm{C}=\mathrm{C}$ st., $\mathrm{CCC}$ b.), 1365 ( $\mathrm{CH}$ acetyl b.), 1218 (CO acetyl st.), 1037 (COC pyranose ring skeletal vibration) 906, 813, 781, 695 (Aromatic $-\mathrm{CH}$ opb.). MS: HRMS (ESI ${ }^{+}$), calcd for $\mathrm{C}_{31} \mathrm{H}_{32} \mathrm{~N}_{3} \mathrm{O}_{11}[\mathrm{M}+$ $\mathrm{H}]^{+}$: 622.203135; found, 622.203997. MW: $621.6 \mathrm{~g} / \mathrm{mol} . \mathrm{mp}$ $\sim 90{ }^{\circ} \mathrm{C}$ (degradation).

2-((4- ( ( ( $(2 R, 3 R, 4 S, 5 S, 6 R)-3,4,5-t$ rihydroxy-6(hydroxymethyl)tetrahydro-2H-pyran-2-yl)oxy)methyl)- $1 H$ 1,2,3-triazol-1-yl)methyl)-1H-phenalen-1-one 21 (PNGIc-B). PNGlc-A (300 mg, $0.48 \mathrm{mmol}$ ) was dissolved in a mixture of $\mathrm{THF} / \mathrm{MeOH}(1: 1)$ with $1 \mathrm{~mL}$ of triethylamine and a drop of 
water, and the reaction was left for $12 \mathrm{~h}$ under stirring at room temperature. The solvents were evaporated, and the crude was purified by column chromatography $\left(\mathrm{CHCl}_{3} / \mathrm{MeOH} 8: 2\right)$ and then lyophilized to yield $201 \mathrm{mg}(0.44 \mathrm{mmol}, 92 \%)$ of a bright yellow powder. ${ }^{1} \mathrm{H}-\mathrm{NMR}$ ( $\left.500 \mathrm{MHz}, \mathrm{CD}_{3} \mathrm{OD}\right): \delta$ (ppm) 8.57 (dd, $J=1.1,7.4 \mathrm{~Hz}, 1 \mathrm{H}), 8.33(\mathrm{dd}, J=0.7,8.1 \mathrm{~Hz}, 1 \mathrm{H}), 8.16$ (s, $1 \mathrm{H}), 8.14(\mathrm{~d}, J=8.2 \mathrm{~Hz}, 1 \mathrm{H}), 7.91(\mathrm{~d}, J=6.8 \mathrm{~Hz}, 1 \mathrm{H})$, $7.83(\mathrm{~s}, 1 \mathrm{H}), 7.81(\mathrm{t}, J=7.7 \mathrm{~Hz}, 1 \mathrm{H}), 7.66(\mathrm{dd}, J=7.2,8.2 \mathrm{~Hz}$, $1 \mathrm{H}), 5.58(\mathrm{~s}, 2 \mathrm{H}), 4.99(\mathrm{~d}, J=12.5 \mathrm{~Hz}, 1 \mathrm{H}), 4.81(\mathrm{~d}, J=12.5$ $\mathrm{Hz}, 1 \mathrm{H}), 4.39$ (d, $J=7.8 \mathrm{~Hz}, 1 \mathrm{H}), 3.88(\mathrm{~m}, 1 \mathrm{H}), 3.67(\mathrm{dd}, J=$ 5.4, $11.9 \mathrm{~Hz}, 1 \mathrm{H}), 3.36(\mathrm{~m}, 1 \mathrm{H}), 3.29(\mathrm{~m}, 2 \mathrm{H}), 3.21(\mathrm{dd}, J=$ 7.8, $9 \mathrm{~Hz}, 1 \mathrm{H}) .{ }^{13} \mathrm{C}-\mathrm{NMR}\left(125 \mathrm{MHz}, \mathrm{CD}_{3} \mathrm{OD}\right): \delta$ (ppm) 185.33, 145.94, 143.06, 137.24, 134.75, 134.53, 134.25, 133.69, 131.98, 130.01, 128.63, 128.43 (2C), 128.18, 126.48, 103.79, 78.19, 78.13, 75.17, 71.77, 63.19, 62.94, 50.42. FT-IR: $\nu$ $\left(\mathrm{cm}^{-1}\right): 3359$ (OH st.), 2875 (Aromatic CH st.), 1637, 1620, 1596, 1567 ( $\mathrm{C}=\mathrm{O}$ st., $\mathrm{C}=\mathrm{C}$ st., CCC b.), 1404 (1,2,3-triazole ring st.), 1361, 1255 ( $\mathrm{C}=\mathrm{C}$ st., $\mathrm{CH}$ b., CCC b.), 1035 (COC pyranose ring skeletal vibration), 812, 779 (Aromatic $-\mathrm{CH}$ opb.). MS: HRMS $\left(\mathrm{ESI}^{+}\right)$, calcd for $\mathrm{C}_{23} \mathrm{H}_{24} \mathrm{~N}_{3} \mathrm{O}_{7}[\mathrm{M}+\mathrm{H}]^{+}$: 454.160877; found, 454. 160507. MW: $453.45 \mathrm{~g} / \mathrm{mol}$. mp 132 ${ }^{\circ} \mathrm{C}$.

\section{ASSOCIATED CONTENT}

\section{SI Supporting Information}

The Supporting Information is available free of charge at https://pubs.acs.org/doi/10.1021/acsomega.0c04172.

${ }^{1} \mathrm{H}$ and ${ }^{13} \mathrm{C}$ NMR characterization data; HRMS results; and UV absorbance, fluorescence, and singlet oxygen data of all the compounds (PDF)

\section{AUTHOR INFORMATION}

\section{Corresponding Author}

Vincent Sol - Universite de Limoges, Laboratoire PEIRENE EA 7500, 87060 Limoges Cedex, France; GDR CNRS 2067, "MAPYRO", Paris, France; ๑ orcid.org/0000-0003-01750156; Email: vincent.sol@unilim.fr

\footnotetext{
Authors

Jérémy Godard - Université de Limoges, Laboratoire PEIRENE EA 7500, 87060 Limoges Cedex, France

Frédérique Brégier - Université de Limoges, Laboratoire PEIRENE EA 7500, 87060 Limoges Cedex, France; GDR CNRS 2067, "MAPYRO", Paris, France; 이이.org/00000002-9880-7616

Philippe Arnoux - Université de Lorraine, Laboratoire Réactions et Génies des Procédes, UMR 7274 CNRS, ENSIC, 54001 Nancy Cedex, France; GDR CNRS 2067, "MAPYRO", Paris, France

Bauyrzhan Myrzakhmetov - Universite de Lorraine, Laboratoire Réactions et Génies des Procédes, UMR 7274 CNRS, ENSIC, 54001 Nancy Cedex, France

Yves Champavier - BISCEm, FR3503 GEIST, Centre de Biologie et de Recherche en Santé (CBRS), 87025 Limoges Cedex, France

Céline Frochot - Université de Lorraine, Laboratoire Réactions et Génies des Procédes, UMR 7274 CNRS, ENSIC, 54001 Nancy Cedex, France; GDR CNRS 2067, "MAPYRO", Paris, France
}

Complete contact information is available at:

https://pubs.acs.org/10.1021/acsomega.0c04172

\section{Notes}

The authors declare no competing financial interest.

\section{ACKNOWLEDGMENTS}

The authors acknowledge "Région Nouvelle-Aquitaine" for financial support, Dr. Cyril Colas (ICOA/CBM, Orléans University) for HRMS analysis, and Dr. Michel Guilloton for manuscript editing.

\section{REFERENCES}

(1) Flors, C.; Nonell, S. Light and Singlet Oxygen in Plant Defense Against Pathogens: Phototoxic Phenalenone Phytoalexins $\dagger$. Acc. Chem. Res. 2006, 39, 293-300.

(2) Echeverri, F.; Torres, F.; Quiñones, W.; Escobar, G.; Archbold, R. Phenylphenalenone Phytoalexins, Will They Be a New Type of Fungicide? Phytochem. Rev. 2012, 11, 1-12.

(3) Elsebai, M.; Ghabbour, H.; Mehiri, M. Unusual Nitrogenous Phenalenone Derivatives from the Marine-Derived Fungus Coniothyrium Cereale. Molecules 2016, 21, 178.

(4) Schmidt, R.; Tanielian, C.; Dunsbach, R.; Wolff, C. Phenalenone, a Universal Reference Compound for the Determination of Quantum Yields of Singlet Oxygen O2 $(1 \Delta \mathrm{g})$ Sensitization. J. Photochem. Photobiol. Chem. 1994, 79, 11-17.

(5) Hidalgo, W.; Duque, L.; Saez, J.; Arango, R.; Gil, J.; Rojano, B.; Schneider, B.; Otálvaro, F. Structure-Activity Relationship in the Interaction of Substituted Perinaphthenones with Mycosphaerella Fijiensis. J. Agric. Food Chem. 2009, 57, 7417-7421.

(6) Cieplik, F.; Späth, A.; Regensburger, J.; Gollmer, A.; Tabenski, L.; Hiller, K.-A.; Bäumler, W.; Maisch, T.; Schmalz, G. Photodynamic Biofilm Inactivation by SAPYR-An Exclusive Singlet Oxygen Photosensitizer. Free Radic. Biol. Med. 2013, 65, 477-487.

(7) Song, R.; Feng, Y.; Wang, D.; Xu, Z.; Li, Z.; Shao, X. Phytoalexin Phenalenone Derivatives Inactivate Mosquito Larvae and Root-Knot Nematode as Type-II Photosensitizer. Sci. Rep. 2017, 7, 42058.

(8) Nonell, S.; González, M.; Trull, F. R. 1H-Phenalen-1-One-2Sulfonic Acid: An Extremely Efficient Singlet Molecular Oxygen Sensitizer for Aqueous Media. Afinidad 1993, 448, 445-450.

(9) Bäumler, W.; Felgenträger, A.; Lehner, K.; Maisch, T.; Regensburger, J.; Santarelli, F. Phenalene-1-One Derivatives, Method for Producing Same and Use Thereof. U.S. Patent 0,039,184 A1, February 6, 2014.

(10) Sandoval-Altamirano, C.; De la Fuente, J. R.; Berrios, E.; Sanchez, S. A.; Pizarro, N.; Morales, J.; Gunther, G. Photophysical Characterization of Hydroxy and Ethoxy Phenalenone Derivatives. J. Photochem. Photobiol. Chem. 2018, 353, 349-357.

(11) Späth, A.; Leibl, C.; Cieplik, F.; Lehner, K.; Regensburger, J.; Hiller, K.-A.; Bäumler, W.; Schmalz, G.; Maisch, T. Improving Photodynamic Inactivation of Bacteria in Dentistry: Highly Effective and Fast Killing of Oral Key Pathogens with Novel Tooth-Colored Type-II Photosensitizers. J. Med. Chem. 2014, 57, 5157-5168.

(12) Bresolí-Obach, R.; Gispert, I.; Peña, D. G.; Boga, S.; Gulias, Ó.; Agut, M.; Vázquez, M. E.; Nonell, S. Triphenylphosphonium Cation: A Valuable Functional Group for Antimicrobial Photodynamic Therapy. J. Biophot. 2018, 11, No. e201800054.

(13) Benniston, A. C.; Bunn, A. Sulfonation of Phenalenone Revisited: Preparation and Characterisation of Sodium $1 \mathrm{H}-$ Phenalene-1-One-5-Sulfonate. J. Chem. Res. 2010, 34, 603-605.

(14) Tabenski, I.; Cieplik, F.; Tabenski, L.; Regensburger, J.; Hiller, K.-A.; Buchalla, W.; Maisch, T.; Späth, A. The Impact of Cationic Substituents in Phenalen-1-One Photosensitizers on Antimicrobial Photodynamic Efficacy. Photochem. Photobiol. Sci. 2016, 15, 57-68.

(15) Jensen, F.; Greer, A.; Clennan, E. L. Reaction of Organic Sulfides with Singlet Oxygen. A Revised Mechanism. J. Am. Chem. Soc. 1998, 120, 4439-4449. 